Running head: Functional diversity indices

\title{
A USER'S GUIDE TO FUNCTIONAL DIVERSITY INDICES
}

\author{
SChleuter D. ${ }^{1}$, DAUfresne M., MASSOl F., AND ARgILlier C. \\ Cemagref, Unité de Recherche Hydrobiologie, 3275 Route de Cézanne, CS 40061, 13182 Aix \\ en Provence, France
}

${ }^{1}$ Corresponding author. E-mail: Diana.Schleuter@web.de 
Abstract. Functional diversity is the diversity of species traits in ecosystems. This concept is increasingly used in ecological research. Yet its formal definition and measurements are currently under discussion. As the overall behavior and consistency of functional diversity indices have never been described so far, the novice user risks choosing an inaccurate index or a set of redundant indices to represent functional diversity.

In our study we closely examine functional diversity indices to clarify their accuracy, consistency, and independency. Following current theory, we categorize them into functional richness, evenness, or divergence indices. We considered existing indices as well as new indices developed in this study. The new indices aimed at remedying the weaknesses of currently used indices (e.g., by taking into account intraspecific variability). Using virtual datasets, we first test whether indices respond to community changes as expected from their category, and second, whether the indices within each category are consistent and independent of indices from other categories. We also test the accuracy of methods proposed for the use of categorical traits.

Most classical functional richness indices either failed to describe functional richness or were correlated with functional divergence indices. We therefore recommend using the new functional richness indices which consider intraspecific variability and thus empty space in the functional niche space. In contrast, most functional evenness and divergence indices performed well with respect to all proposed tests. For categorical variables, we do not recommend blending discrete and real-valued traits (except for indices based on distance measures) since functional evenness and divergence have no transposable meaning for discrete traits. Nonetheless, species diversity indices can be applied to categorical traits (using trait levels instead of species) in order to describe functional richness and equitability.

Key words: functional richness; functional evenness; functional divergence; species richness; morphological traits; categorical variables. 
Schleuter, D., Daufresne, M., Massol, F., and Argillier, C. (2010) A User's guide to functional diversity indices, Ecological Monographs, vol. 80, $\mathrm{n}^{\circ} 3,469-484$.

\section{INTRODUCTION}

Biodiversity is commonly expressed through indices based on species richness and species abundances (Whittaker 1972, Lande 1996, Purvis and Hector 2000). Recently, however, studies focused on diversity have begun to incorporate the concept of functional diversity. In contrast to species diversity, functional diversity measures the distribution and the range of what organisms do in communities and ecosystems, and thus considers the complementarity and redundancy of co-occurring species (Díaz and Cabido 2001, Petchey and Gaston 2006). Functional diversity is commonly assumed to be a better predictor of ecosystem productivity and vulnerability than species diversity (Tilman et al. 1997, Hulot et al. 2000, Díaz and Cabido 2001, Heemsbergen et al. 2004).

Including species' functions in the measurement of biodiversity is a relatively recent approach. Since 1990, the number of publications based on functional diversity has been steadily increasing (Fig. 1). Although the concept of functional diversity itself is relatively simple to understand, its increasing importance in biodiversity studies has revealed that measuring it is a complex endeavor: when studies focused on species diversity only need to count individuals from different species (i.e., sort them into several categories), functional diversity studies have to describe a multi-dimensional cloud of points in trait space (i.e., each coordinate corresponds to a measured trait), each point representing an individual or a species. Several methods have recently been proposed to help identify the necessary measures of functional diversity (reviewed in Petchey and Gaston 2006 and Ricotta 2005, Podani and Schmera 2007, Villéger et al. 2008). Two main approaches have emerged: on the one hand, functional groups can be defined based on few behavioral/morphological characteristics (e.g., diet affinities, food acquisition methods, preferred habitat) and the observed species are assigned to different functional categories (Bremner et al. 2003, Stevens et al. 2003, Petchey and Gaston 2006). These data can be further processed with conventional species diversity indices (Functional Group Richness, Shannon Index, Simpson Diversity Index, etc.) (Stevens et al. 2003). This approach is suitable for macro-ecological studies since information on species' assignment to functional groups is available for a broad range of species and generally easy to obtain. Furthermore, such studies only need a low level of detail in contrasting species traits. On the other hand, functional diversity can be calculated based on specific functional traits measured for each species. This approach promises a finer resolution (Bremner et al. 2003, Petchey and Gaston 2006), but trait values are more difficult to obtain than information on functional group memberships. For instance, it is easier to categorize fish 
Schleuter, D., Daufresne, M., Massol, F., and Argillier, C. (2010) A User's guide to functional diversity indices, Ecological Monographs, vol. 80, $\mathrm{n}^{\circ} 3,469-484$.

species by their general diet than to obtain measurements on their size, gape width, stomach length, etc. Functional traits can be morphological traits which represent adaptations to different diets or habitats, physiological traits (e.g., temperature tolerance), reproductive traits (e.g., number of eggs and egg diameter) or behavioral traits (e.g., migratory behavior or parental care) (Bremner et al. 2003, Dumay et al. 2004, Lepš et al. 2006). Because most of these measurements are real-valued (i.e., not discrete) and more than one trait is used to describe the different functions, the indices commonly used to measure species diversity cannot be applied (e.g., Simpson Diversity Index).

To make use of multiple trait measurements, Bremner et al. (2003) compared functional trait compositions between sites using principal component (PCA) or co-inertia analyses. However, this approach is comparative and not based on functional diversity per se, and therefore does not give absolute insight into the distribution of traits within a specific site. Alternatively, species diversity indices have now been transposed to functional diversity measurements, and several new indices have been proposed (e.g., Mason et al. 2005, Ricotta 2005, Petchey and Gaston 2006, Villéger et al. 2008). These indices usually describe two broad aspects of functional diversity: (i) how much of the functional niche space is filled by the existing species (functional richness), and (ii) how this space is filled (functional evenness, functional divergence/variance).

Using functional diversity indices, however, entails several methodological problems. The first difficulty is the selection and the treatment of the traits: e.g., how many and which traits to use, how to weigh them and how to combine them (Lepš et al. 2006, Petchey and Gaston 2006). Some solutions to these problems have been discussed and proposed by Lepš et al. (2006). The second set of problems is related to the indices themselves: i.e., do the indices measure exactly what the user wants to describe? Are the chosen indices independent from each other? Will diversity be measured for a single trait only or for a multivariate trait data set? Does the dataset contain categorical and continuous variables? It is particularly important that these problems are considered carefully because ecological theories are developed and confirmed based on these results.

Some properties of selected indices were specified by Petchey and Gaston (2006) and Ricotta (2005), but new indices have been published since then (e.g., Cornwell et al. 2006, Podani and Schmera 2007, Villéger et al. 2008) and although the importance of intraspecific specialization and variability is clearly acknowledged (Bolnick et al. 2003), it has rarely been considered in the formalization of functional diversity. Moreover, a direct comparison of the different indices and their correlations with each other is still missing, and the user of 
Schleuter, D., Daufresne, M., Massol, F., and Argillier, C. (2010) A User's guide to functional diversity indices, Ecological Monographs, vol. 80, $\mathrm{n}^{\circ} 3,469-484$.

functional diversity still faces the problems described above when selecting an index. The aim of this study was therefore:

(i) to describe the main properties of the different functional diversity indices;

(ii) to propose new indices which enhance and supplement existing ones (e.g., accounting for intraspecific variability);

(iii) to test and compare the accuracy of all these indices in defined scenarios;

(iv) to measure the correlations among all these indices;

(v) to summarise the results of (i)-(iv) in a table to facilitate the selection of an appropriate index for the user.

\section{METHODS}

\section{Functional diversity indices}

The functional diversity of a community approached through the measurements of traits is usually described by three kinds of indices which can be combined to calculate different facets of functional diversity (Mason et al. 2005, Villéger et al. 2008, examples for application: Mason et al. 2007, Mason et al. 2008): functional richness (FR), functional evenness (FE) and functional divergence (FD). FR indices generally measure how much niche space is filled, FE and FD indices how this space is filled. Defining functional diversity indices, however, is not a simple task since there is no natural way of describing richness, evenness, or divergence when individuals are not assigned to classes (i.e., species), but rather described by their traits. First, any index should reflect the verbal definition of its properties. Second, FR, FE and FD indices aim at measuring different aspects of functional diversity and should therefore be uncorrelated (independent) in a random community.

There are nine indices available in the literature to calculate functional diversity on the basis of measured traits, which we describe and test in this study: three FR indices (first described by: Petchey and Gaston 2002, Mason et al. 2005, Cornwell et al. 2006), two FE indices (Mouillot et al. 2005, Villéger et al. 2008) and four FD indices (first described by: Rao 1982, Mason et al. 2003, Lepš et al. 2006, Villéger et al. 2008). Each index group contains one- and multi-dimensional indices. Despite their multiplicity, these indices still miss some important points, e.g. FR indices do not consider individual variability. Indeed, individual variability in functional diversity has been approached through the expansion of existing indices for the use of individuals (Lepš et al. 2006, Cianciaruso et al. 2009). However, indices which specifically account for the use of intraspecific variation (using 
Schleuter, D., Daufresne, M., Massol, F., and Argillier, C. (2010) A User's guide to functional diversity indices, Ecological Monographs, vol. 80, $\mathrm{n}^{\circ} 3,469-484$.

means and intraspecific variability as input, not individual trait values) have only be proposed for two FD indices (Lepš et al. 2006). To fill these gaps, we propose three additional indices (two FR and one FD indices), which are also described and tested in this study.

\section{Functional richness}

FR indices measure how much of the niche space is occupied by the species present. They are usually interpreted by ecologists as an indicator for potentially used/unused niche space and thus e.g. for productivity, buffering against environmental fluctuations or vulnerability to invasion (Mason et al. 2005). FR is naturally positively correlated to the number of species present (the more species there are, the larger the functional space occupied when species traits are somewhat randomly distributed). However, two communities with the same number of species may have different FR when functional traits of species are more closely clustered in one community than in the other. FR is not weighted by species abundance.

\section{One-dimensional indices}

Mason et al. (2005) suggested using the functional range $\left(F R_{R}\right)$ as a measure of FR (Table 1: IN 1.1). $F R_{R}$ is the relative range of a trait that is filled by a community at a site compared to the range of the trait for all communities together. In this way $F R_{R}$ is restricted between 0 and 1 and becomes comparable for differently scaled traits. Please note, however, that the value for an individual site is not absolute but might change when the overall range changes (e.g., by the addition of a new site with species that differ in trait values). The community's range is calculated based on species' mean trait values by simply subtracting the lowest from the highest mean trait value at a site. The absolute range is calculated accordingly for all sites together. If more than one trait is used, the mean community range is then the mean of all traits.

Newly proposed index: Neither individual variability, nor gaps in trait space are accounted for by $F R_{R}$. This is an issue when individual variability between sites differs and when functionally exceptional species are added to the community, or when species with trait values within the range are missing. We therefore propose a new one-dimensional functional richness index $\left(F R_{I S}\right)$ (Table 1: IN 1.2). $F R_{I S}$ is based on species' trait variability: instead of the community's trait range, $F R_{I S}$ is based on the union of the species' trait ranges (and thus considers individual variability). It is calculated as the union of species' trait ranges at one site, relative to the union of species' trait ranges for all sites together (see $F R_{R}$ ). When calculating $F R_{I S}$ the species' trait range can be calculated using two species/trait matrices as 
Schleuter, D., Daufresne, M., Massol, F., and Argillier, C. (2010) A User's guide to functional diversity indices, Ecological Monographs, vol. 80, $\mathrm{n}^{\circ} 3,469-484$.

input tables, containing the species' minimum and maximum trait values, respectively. With this method, however, the range depends on the number of individuals measured. We therefore suggest using more conservative values, e.g., the $10^{\text {th }}$ and $90^{\text {th }}$ percentiles, confidence intervals or the mean species trait value minus and plus the standard deviation. For further details see Appendix A. A script in R for this index is available at:

http://www.cemagref.fr/le-cemagref/lorganisation/les-centres/aix-en-provence/urhyax/scripts/ecology_schleuter2009/.

\section{Multi-dimensional indices}

The multivariate counterpart of $F R_{R}$ is the functional volume $F R_{V}$ (Cornwell et al. 2006) (Table 1: IN 1.3). $F R_{V}$ calculates the volume of trait space with the convex hull volume, which represents the smallest convex hull that encloses all species. With a complex algorithm, the most extreme points (vertices) can be determined and the volume encompassed by these vertices is calculated (TraitHull program http://www.pricklysoft.org/software/ traithull.html programmed in Python (Cornwell et al. 2006), and for R on http://www.ecolag.univmontp2.fr/software (Villéger et al. 2008)). To calculate this index, the number of species must always exceed the number of traits.

A second existing multi-dimensional FR index is the dendrogram-based index $F R_{D}$ (Petchey and Gaston 2002) (Table 1: IN 1.4). This index measures the extent of species complementarity based on a trait distance matrix (Petchey and Gaston 2002), a property equivalent to FR (Mouillot et al. 2005). A dendrogram is computed by hierarchical clustering, the functional richness is then the sum of the branch lengths of species present. There has been discussion in the literature on which distance measure and cluster method is best to calculate this index (Podani and Schmera 2006, Petchey and Gaston 2007, Podani and Schmera 2007, Mouchet et al. 2008). Here, we used the method developed by Mouchet et al. (2008) (R program available at http://www.ecolag.univ-montp2.fr) that computes dendrograms based on two distance matrices and seven clustering methods, which belong to the family of hierarchical agglomerative classifications, and then selects the combination (including a consensus tree) which best represents the species distribution in functional trait space.

Newly proposed index: As for $F R_{R}, F R_{V}$ does not consider gaps in functional trait space. We therefore developed a multivariate counterpart to $F R_{I S}: F R_{I m}$ (Table 1: IN 1.5). FR Im is specifically designed to account for individual variability and for gaps in the multidimensional functional trait space. The idea is to compute an equivalent "range union" (as for 
Schleuter, D., Daufresne, M., Massol, F., and Argillier, C. (2010) A User's guide to functional diversity indices, Ecological Monographs, vol. 80, $\mathrm{n}^{\circ} 3,469-484$.

$\left.F R_{I s}\right)$ across species present in a community. To do so, each species $s$ is assigned a function on trait space $\left(f_{s}\right)$ which indicates whether a particular point in trait space is (or not) occupied by species $s$ (that is, whether species $s$ trait values encompass this point). Here, we chose a simple form for $f_{s}$ functions that uses information on both mean trait values and trait variancecovariance matrices for each species. $F R_{I m}$ is then obtained as the integral of the maximum of all $f_{s}$ functions (integrated over studied trait space). For further details see Appendix B. A script in Mathematica to calculate this index is available at http://www.cemagref.fr/lecemagref/lorganisation/les-centres/aix-en-provence/ur-hyax/scripts/ecology_schleuter2009/.

\section{Functional evenness}

FE indices measure whether mean species traits are distributed regularly within the occupied trait space, i.e. with equal distances between nearest neighbors and equal abundances (a high FE index usually means a very regular distribution; a low FE index, the existence of separate clouds of species and/or abundances). FE indices are generally used to indicate under/over-utilization of resources and thus again productivity, reliability and vulnerability to invasion (Mason et al. 2005). This index group includes species' abundances in its calculation.

One-dimensional index

Based on Bulla's index to measure species' evenness (Bulla 1994), the $F E_{s}$ index (Mouillot et al. 2005) measures for each trait separately how evenly the trait values of all species present are distributed (Table 1: IN 2.1). First, the absolute, relative distances between the mean species trait values, in order of increasing values, is calculated and weighted by the sum of the relative species abundances. Second, if the distance is greater than $1 /(S-1)$ (S: species richness) it is replaced by $1 /(S-1)$, the distance, which is obtained for an optimal even distribution (Mouillot et al. 2005). $F E_{s}$ is 1 if the distance between nearest neighbor species is exactly $1 /(S-1)$ and all species have the same abundances. The more a community differs from the optimal distribution in terms of abundance and trait difference, the lower gets $F E_{s}$. When trait space is multi-dimensional, the community's evenness is the average of the $F E_{s}$ calculated for each trait.

Multi-dimensional index 
Schleuter, D., Daufresne, M., Massol, F., and Argillier, C. (2010) A User's guide to functional diversity indices, Ecological Monographs, vol. 80, $\mathrm{n}^{\circ} 3,469-484$.

The multivariate equivalent of $F E_{s}$ is $F E_{m}$ (Villéger et al. 2008) (Table 1: IN 2.2). Instead of using the absolute distances between the species' trait values for each trait separately, this index uses the abundance-weighted distances between all species pairs to calculate first the minimum spanning tree (MST) that links all the species in a multi-dimensional trait space. The index then measures the regularity of the MST branch lengths, according to $F E_{s}$ (i.e., comparison with the optimal branch length distribution).

\section{Functional divergence}

FD indices, finally, measure the variance of the species' functions and the position of their clusters in trait space (a high FD is caused by the clustering of species and/or abundances at the edges of the traits' space). FD indices find application for indicating the degree of resource differentiation and thus competition (Mason et al. 2005), but they can also indicate a predominance of extreme species. As FE, FD includes species' abundances in its calculation.

\section{One-dimensional divergence}

Functional divergence can be calculated as the abundance-weighted functional variance using mean species values (Mason et al. 2003). Mason et al. (2003) suggested log transforming the trait values before calculating the variance $\left(F D_{v a r}\right)$ (Table 1: IN 3.1) and to use species relative abundances as abundance weight. If more than one trait is used, $F D_{v a r}$ is calculated for each trait separately and then averaged over traits. They recommend then using an arctangent transformation in order to restrict the index between 0 and 1 . If species and/or abundances are clustered around the mean trait value, $F D_{\text {var }}$ is low; if they are clustered at the edges of the community $F D_{v a r}$ is high.

$F D_{v a r}$ is not applicable if the dataset contains 0 -values. To account for this problem, we propose using simply the abundance-weighted variance without log transformation $\left(F D_{\sigma}\right)$ (Table 1: IN 3.2) (Lepš et al. 2006). Since the variance is scale-dependent, traits should be standardized (e.g., centering and scaling by standard deviation) in case the trait space is multidimensional and the different traits have different scales. Another possibility is to use the coefficients of variation instead (i.e., standard deviations divided by means). Lepš et al. (2006) suggest to include intraspecific variability in this index by adding the abundanceweighted intraspecific variance to the interspecific variance.

Newly proposed index: Since FD can also be understood as the relative range of the trait clustering, we propose a new one-dimensional index of functional divergence $\left(F D_{s}\right)$. $F D_{s}$ calculates the range of the $\mathrm{z}^{\text {th }}$ percentiles (e.g., $25^{\text {th }}$ percentile $\mathrm{Q}_{1}$ and $75^{\text {th }}$ percentile $\mathrm{Q}_{3}$ ) 
Schleuter, D., Daufresne, M., Massol, F., and Argillier, C. (2010) A User's guide to functional diversity indices, Ecological Monographs, vol. 80, $\mathrm{n}^{\circ} 3,469-484$.

relative to the overall range of each trait (Table 1: IN 3.4). The species abundance is accounted for by replicating the mean trait value of a species $i$ times its abundance. This approach is conceptually different, since it is based on the relative span of the trait cluster and not on the variance. Low $F D_{s}$ values indicate that half of the individuals in the community occupy a very confined functional space, independent of the position of that cluster along the trait axis; high values instead suggest that the functional space is more densely occupied at both its edges). For further details see Appendix C. A script in R to calculate this index is available at http://www.cemagref.fr/le-cemagref/lorganisation/les-centres/aix-en-provence/urhyax/scripts/ecology_schleuter2009/.

\section{Multivariate divergence}

The most common multivariate index of FD is Rao's quadratic entropy $F D_{Q}$ (Rao 1982, Champely and Chessel 2002, Ricotta 2005) (Table 1: IN 3.5). This index calculates the abundance-weighted variance of the dissimilarities between all species pairs. It is based on the Simpson Diversity Index (Simpson 1949) to calculate species diversity and weighs the traitbased distances between pairs of species $\left(\operatorname{dist}\left(s, s^{\prime}\right)\right)$ by the product of their relative abundances. Lepš et al. (2006) suggest calculating the species' pairwise dissimilarities through the sum of their overlaps for each trait. In this way, individual variability is included in this index and categorical and continuous variables can be mixed. Rao's quadratic entropy can also be calculated for single traits, the average of which leads to the same result as the multivariate approach, if the distance measure used is unchanged by averaging (e.g., Euclidean distance) (Lepš et al. 2006). Since Walker, Kinzig and Langridge's functional attribute diversity (1999) differs from Rao's quadratic entropy only in the way the distance matrix is calculated, it was not tested as a separate index in this study.

Villéger et al. (2008) proposed a new multivariate measure for functional divergence $\left(F D_{m}\right)$. Based on the vertex species $V$ of the convex hull (see $F R_{v}$ ), this index first determines the centre of gravity $G$ of the convex hull (Table 1: IN 3.6). It then computes the abundanceweighted deviances $\Delta d$ of each species present from the species' mean distance of the centre of gravity. In a last step, the index is restricted between 0 and $1 . F D_{m}$ is low when species/ abundances are close to the centre of gravity and high when species and/or abundances are higher at the vertices of the convex hull. Since this index is based on the calculation of the convex hull, the same assumptions as for the calculation of $F R_{V}$ must be met. 
Schleuter, D., Daufresne, M., Massol, F., and Argillier, C. (2010) A User's guide to functional diversity indices, Ecological Monographs, vol. 80, $\mathrm{n}^{\circ} 3,469-484$.

\section{Transformation of trait data}

Transformations of the original data should be avoided whenever possible. Nonetheless, one should always consider that some indices are not applicable to differently scaled traits (e.g., $F D_{\sigma}$ ). If at least one trait is scaled differently, all traits should be transformed; otherwise this trait might have too little or too much weight in the index calculation. One possibility is to transform a trait that differs in several orders of magnitudes from the others using an algebraic function such as the logarithm (e.g, number of seeds in plants or number of eggs in fishes). Another possibility is to standardize the trait values in respect to the others, e.g., centering and scaling the trait by its standard deviation. This transformation has to be done for the overall data set and not on potential sub-samples (e.g., at different study sites). The subsamples should then be drawn from the transformed trait matrix. For indices which calculate relative index values for each trait separately (e.g., $F R_{R}, F R_{I s,} F D_{s}$, etc.) and for onedimensional indices, which range between 0 and 1 (e.g., $F E_{s}, F D_{\text {var }}$ ), the data need not to be transformed. Different transformation methods and their pros and cons are summarized in Lepš et al. (2006).

\section{Accuracy of the indices}

The first criterion for the quality of an index (accuracy) is the match between the way it actually behaves and the verbal definition of its properties (FR, FE, FD). This was tested in our study using an artificial data set (up to 25 species, two traits). We manipulated species composition and abundances in five tests (T1-T5) (Fig. 2) to compare the observed and expected changes of index values. Trait values were integer numbers between 1 and 5 for trait 1 , and between 1 and 8 for trait 2 . We assumed a standard deviation of 0.2 and a maximum deviation from the mean equal to 0.4 for all species and traits. In all tests, the initial species richness was 25, apart from T1, where it was 24. In T1 and T2 and, if not stated differently, in T3-T5, species abundance was set to 1 for all species.

The main aim of T1 and T2 was to test the effect of empty space in the trait space on the behavior of functional richness indices. In T1, we tested the effect of adding one species, with varying distance between the added species and the existing community (Fig. 2, T1). In T2, we removed nine species from the initial community. We removed these species so that either one trait value was eliminated completely, once at the outer edge of the community and once within the trait space (Fig. 2, T2 a and b), or the removed species were chosen in the middle of the trait space so that each trait value was present at least once (Fig. 2, T2 c). 
Schleuter, D., Daufresne, M., Massol, F., and Argillier, C. (2010) A User's guide to functional diversity indices, Ecological Monographs, vol. 80, $\mathrm{n}^{\circ} 3,469-484$.

In T3-T5, the influence of varying species abundances on functional evenness and divergence was tested. In T3, we increased the abundance of one species stepwise from 1 (initial community) to 2, 25 and 250 individuals to test for the influence of the change in the abundance of one species (Fig. 2, T3). In T4, the influence of the position in trait space of a dominating species (25 individuals) was tested (Fig. 2, T4). In T5, we increased the distance between two dominating species (25 individuals each), starting from an initial community in which the abundance of only one species was set to 50 individuals to simulate two identical species.

All indices were calculated for the initial community and for the different scenarios. The change in index values of the scenarios compared to the initial community was evaluated semi-quantitatively. We used the symbols,-+ and $=$ to indicate whether the calculated value was higher, lower or equal compared to the initial community. The symbols were replicated to give a raw quantitative view of the changes $(++,+++$ with $+<++<+++;,--,---$ with $---<--$ $<-)$.

\section{Indices correlation}

The correlations among the different indices were tested using random communities. We computed 1,000 randomizations for 14 different species richness levels (as multiples of 5 from 5 to 70) and three different numbers of traits (three, five, ten). The total number of treatments was $42(14 \times 3)$. Trait values were generated using uniform distributions between 0 and 1 . The intraspecific standard deviation was considered to be $10 \%$ of the randomized trait value. Species abundances were randomized with a uniform distribution between 1 and 100 for each randomized trait matrix.

All indices described were calculated for each of the 42,000 random communities, apart from $F R_{I m}$, which was only calculated for the three-trait simulation. Actually, its computation time was very long on the computers used in this study and it increased exponentially with the number of traits used.

To provide an overview of the relationships between different community indices, we used ordination techniques (e.g., Principal Component Analysis), which are known to perform well when summarizing complex data (Lebart et al. 2000). Since we had to compare a set of 42 matrices of 1,000 rows (randomized communities) and 12 columns (indices), a single matrix-based approach was not appropriate. As a consequence, for each of the three trait levels, we used a multi-table ordination technique (e.g., Escofier and Pages 1994, Lavit et al. 1994, Chessel and Hanafi 1996) to assess the common structure of the 14 species richness- 
Schleuter, D., Daufresne, M., Massol, F., and Argillier, C. (2010) A User's guide to functional diversity indices, Ecological Monographs, vol. 80, $\mathrm{n}^{\circ} 3,469-484$.

specific matrices. We performed a STATIS analysis (Lavit et al. 1994) to summarize the link between the different indices while removing the potential effect of species richness. This method is based on the optimization of the average ordination of the species richness-specific ordinations. The first step of STATIS consisted in calculating a matrix of scalar products between indices for each of the 14 level of species richness. In a second step, the 14 rows x 14 columns matrix of the pairwise vectorial correlation coefficients (RV coefficients) between the scalar products' matrices was computed. The RV coefficient ranges from 0 to 1 and evaluates the extent to which two matrices share a common structure (Robert and Escoufier 1976). Then the matrix of RV values was diagonalized and the 14 coefficients of the first eigenvector were used to weight the 14 matrices of the scalar product between indices. A mean table of maximum inertia (called the reference structure afterwards) was subsequently computed as the weighted sum of the matrices of the scalar product between indices. By weighting the sum, greater importance was given to tables with similar structures, whereas lesser importance was given to the other tables. Finally, a PCA was performed on the reference structure. It provided the graphical representation of the common structure of the indices derived from the 14 species richness-specific tables.

Two groups of statistics synthesized the relevance and the efficiency of STATIS. The first statistics were the RV coefficients between two species richness-specific tables. The second statistical procedure used was the squared cosines $\left(\cos ^{2}\right)$ of the angles between the first axis scores of separate Principal Component Analyses performed on each species richness-specific table and the first axis scores of the reference structure. This evaluates the match between the species richness-specific tables and the reference structure by using synthetic auxiliary variables.

\section{Categorical variables}

All the indices proposed so far (except those based on a distance matrix) cannot be computed for categorical variables. To address this problem, it is recommended in the literature to transform the data set from categorical to continuous variables via distance matrices and ordination methods, which allow a mix of continuous and categorical variables as inputs. Villéger et al. (2008) proposed calculating the Gower distance and then computing a principal coordinate analysis (PCoA). The trait values thus transformed (principal coordinate axis) can then be used to calculate the different functional diversity indices. Next to using the Gower distance with a PCoA, Hill and Smith's method can also be used (Hill and 
Schleuter, D., Daufresne, M., Massol, F., and Argillier, C. (2010) A User's guide to functional diversity indices, Ecological Monographs, vol. 80, $\mathrm{n}^{\circ} 3,469-484$.

Smith 1976). This ordination technique combines discrete and continuous variables in a single analysis. If all variables are discrete, it is reduced to a simple correspondence analysis.

Although it is not really correct to transform categorical traits to continuous ones for the use of indices designed for real-valued variables, we consider these methods because they are commonly applied. Since continuous trait-based indices cannot be calculated for categorical traits it is impossible to assess the true effect of the transformation on the outputs (i.e., to compare the outputs for transformed and untransformed trait values). As a consequence, we only pseudo-tested the effects of these transformations using continuous traits as input. In this way, the normally calculated indices can serve as a reference value. As described above, we computed 1,000 randomizations for six different species richness levels (in multiples of 10 from 10 to 60 ) with three traits. We then calculated all indices (i) with the original dataset (ii) with the dataset transformed via the Gower distance and PCoA (Podani and Schmera 2006, Villéger et al. 2008), and (iii) with the data set transformed using Hill and Smith's method (Hill and Smith 1976). The common structure of the three calculation methods was then assessed for each species richness level separately, using the RV values (i.e. the correlation coefficient between two tables) obtained from the method-specific tables.

All calculations and tests were carried out using the program $\mathrm{R}$ (R Development Core Team 2008). The STATIS analysis and the transformation via the Hill and Smith method and PCoA were computed using the ade4 package (Chessel et al. 2004, Dray et al. 2007).

\section{RESULTS}

\section{Accuracy of the indices}

Testing whether the indices behave according to the properties of the index group they have been assigned to (FR, FE, FD) reveals that, among the FR indices, only two of them $\left(F R_{I S}\right.$ and $\left.F R_{I m}\right)$ accurately reflect the expected changes in functional richness (see Table 2: T1 and T2), because these indices consider empty space in the trait distribution of a community. However, $F R_{I s}$ is only applicable to one-dimensional situations, while $F R_{I m}$ well reflects functional richness in a multi-dimensional space. The results from scenarios $\mathrm{T} 1 \mathrm{c}$ and T2 a and $b$ show that when one trait value is missing in the entire dataset, both indices decrease. However, in a multi-dimensional space, when none of the trait values of the removed species are unique, but their combination is, $F R_{I m}$ is the only index which reflects these gaps properly (Fig. 2, Table 2: scenario a in T1, scenario c in T2). In contrast, indices such as functional 
Schleuter, D., Daufresne, M., Massol, F., and Argillier, C. (2010) A User's guide to functional diversity indices, Ecological Monographs, vol. 80, $\mathrm{n}^{\circ} 3,469-484$.

range or volume $\left(F R_{R}, F R_{V}\right)$ only reflect a decrease in functional richness when species are removed at the edge of the community. $F R_{D}$, the dendrogram-based index for functional richness is furthest from the expected results for functional richness.

Among the two FE indices, the multivariate index $F E_{m}$ behaves more adequately than its one-dimensional counterpart $F E_{s}$ and matches the expected results quite well. Thus, $F E_{m}$ can be considered an appropriate index (Table 2). However, this index fails to respond adequately in some cases, for example when species in the centre of the community are added or subtracted (T1 scenario a and T2 scenario c). Species traits are then not evenly distributed over the entire functional space, but concentrated at the edges of the community, and thus the evenness is theoretically lower than in the initial community. Yet, $F E_{m}$ remains equal because the distribution of the branch lengths of the minimum spanning tree (the distance to the nearest neighbors) does not change. The one-dimensional index $F E_{s}$ does not represent the distribution of species in a multi-dimensional trait space, but it reflects the evenness of the distribution for a single trait well (results not shown) and can be used if only one trait is considered.

All FD indices adequately match expectations. Even one-dimensional indices, averaged over all traits, accurately reflect changes in a multi-dimensional space (Table 2). Only in T1 do FD indices react differently: as expected, $F D_{\sigma}$ and $F D_{v a r}$ increase when a species outside of the initial community is added, whereas $F D_{Q}, F D_{m}$ and $F D_{s}$ decrease.

\section{Indices correlation}

Species richness has a clear effect on the different indices, either in terms of variance or mean values (Fig. 3). Nevertheless, for all trait levels, there is a high similarity between the species richness-specific tables (RV ranging from 0.885 to 0.996 , from 0.945 to 0.998 , and from 0.962 to 0.998 for three, five and ten traits, respectively). In addition, the $\cos ^{2}$ confirms that the different reference structures reflect the structures of the individual species richnessspecific tables ( $\cos ^{2}$ ranging from 0.905 to 0.944 , from 0.920 to 0.940 , and from 0.924 to 0.941 for three, five and ten traits, respectively). The lowest $\cos ^{2}$ values are systematically found for the lowest levels of species richness (five, followed by ten) because of the higher variance of most indices at these species richness levels (see Fig. 3).

The reference structures over the different species richness levels are very similar for all trait levels (three, five or ten) (Fig. 4), confirming that there are several independent index groups which describe functional diversity. However, instead of the expected three axes corresponding to FR, FE and FD indices, five axes are needed to explain the majority of the 
Schleuter, D., Daufresne, M., Massol, F., and Argillier, C. (2010) A User's guide to functional diversity indices, Ecological Monographs, vol. 80, $\mathrm{n}^{\circ} 3,469-484$.

variance (74\%) when $F R_{I m}$ is included (three traits), and four axes without this index $(77 \%$ and $78 \%$ for five and ten traits, respectively).

The first axis is mainly correlated to the FD indices $\left(F D_{\sigma}, F D_{s}, F D_{Q}\right.$ and $F D_{m}$, Table 3, Fig. 4). The fifth FD index $\left(F D_{v a r}\right)$ is also correlated to the first axis, but with the second axis as well and it is overall more highly correlated to the FR indices $F R_{R}$ and $F R_{V}$ than to the other FD indices. Next to $F D_{\text {var }}$ the second axis is correlated mainly to some of the FR indices $\left(F R_{R}, F R_{V}\right.$, and partly $\left.F R_{I s}\right)$. The third axis represent functional evenness $\left(F E_{s}\right.$ and $\left.F E_{m}\right)$ and the remaining two FR indices $\left(F R_{I m}\right.$ and $\left.F R_{D}\right)$ are best represented by the fourth and fifth axes, respectively (Table 3, Fig. 4).

Note that $F R_{V}$ is not fully independent of $F D_{Q}$ and $F D_{s}$ (r ranging from 0.09 to 0.59 for $F D_{s}$ and from 0.21 to 0.71 for $F D_{Q}$ depending on the species richness level and the number of traits), despite distance in the F1 $\times$ F2 factorial plane of the STATIS analysis. In addition, the correlation between $F R_{I S}$ and $F R_{I m}$ decreases with increasing species richness (from $\mathrm{r}=0.61$ in a community with five species to $r=0.00$ in a community with 25 species).

\section{Categorical variables}

One- and multi-dimensional indices react differently to the transformation from discrete to continuous variables. Therefore, correlations between the method-specific tables (RV values) have been computed separately for these two index groups. For multi-dimensional indices, we have found a high similarity between the index tables calculated with the raw data and the differently treated data sets. The transformation via the Hill and Smith method performs slightly better (RV range dependent on species richness between 0.897 and 0.956 for Gower distance and PCoA transformed data, and between 0.997 and 0.999 for data transformed with the Hill and Smith method). That the results were worse for the transformation via the Gower distance and PCoA is mainly imputable to the calculation of $F R_{V}$ ( $\mathrm{r}$ with the index calculated with untransformed values ranged from 0.13 to 0.60 , depending on species richness) and $F D_{Q}$ ( $\mathrm{r}$ around 0.5 ).

For the one-dimensional indices, neither of the transformation methods performs well (RV ranging between 0.605 and 0.894 for the transformation via Gower distance and PCoA and between 0.688 and 0.897 for transformation via the Hill and Smith method). 
Schleuter, D., Daufresne, M., Massol, F., and Argillier, C. (2010) A User's guide to functional diversity indices, Ecological Monographs, vol. 80, $\mathrm{n}^{\circ} 3,469-484$.

\section{DISCUSSION}

\section{Performance of the indices}

The functional diversity indices described and tested in this study performed quite differently. The quality of the indices aimed at describing the same aspect of functional diversity differed markedly, especially within the group of the FR indices.

In our view, the main criterion for the selection of an index is whether it accurately measures what it is intended to describe. This was the case for all FD indices irrespective of whether they were one- or multi-dimensional as well as for the two FE indices. However, while the multi-dimensional index $F E_{m}$ performed quite well in describing the evenness in the two-dimensional space, its one-dimensional counterpart $F E_{s}$ was only able to measure evenness when a single trait was considered. In contrast, the FR indices differed most strongly in their quality: the only indices which reflected the expected changes in FR, when species were removed within the functional trait space, were the two indices which consider gaps in the functional trait space $\left(F R_{I s}\right.$ and $\left.F R_{I m}\right) . F R_{R}$ and $F R_{V}$ only partly reflected what is considered functional richness (only if there was a continuously filled trait space and species were removed or added at the edges of the community), while the results obtained from the index $F R_{D}$ did not match the expected values. This index may work in some cases (Petchey and Gaston 2006), but it failed to pass the tests proposed here, maybe due to the number of traits and/or the number of species used. The behavior of this index is thus difficult to understand and we suggest rethinking its interpretation.

These results were confirmed by the multi-table ordination analysis (STATIS): instead of three principal component axes, which were expected to correspond to the three index groups FR, FE and FD, we found that five axes were needed to explain most of the variance: three for FR, and one for FD and FE. That three axes were needed to explain the variance of FR indicates that the existing FR indices describe independent aspects of functional diversity: $F R_{R}$ and $F R_{V}$ form one group, which describes the traits' range/volume; $F R_{I m}$ measures the occupation and span of trait space; $F R_{D}$, which represents the branch length of a dendrogram, is independent of the other FR indices, but what it actually measures is difficult to determine. $F R_{I s}$ was not represented by a single axis, but was partly correlated with $F R_{R}, F R_{V}$ and $F R_{I m}$, because $F R_{I s}$ accounts for gaps in trait space (as $F R_{I m}$ ) but fails to take into account the multidimensional nature of trait space, so that gaps are severely underestimated when the number of traits is high. 
Schleuter, D., Daufresne, M., Massol, F., and Argillier, C. (2010) A User's guide to functional diversity indices, Ecological Monographs, vol. 80, $\mathrm{n}^{\circ} 3,469-484$.

The second criterion for the selection of an adequate index is that the chosen index is independent of indices describing other aspects of functional diversity. This criterion is met by the two FE indices, but not by all the FR and FD indices: $F R_{R}$ and $F R_{V}$ both correlated with $F D_{\text {var }}$ and $F R_{V}$ also correlated with $F D_{s}$ and $F D_{Q}$ (Table 4). This strongly suggests that $F D_{\text {var }}, F R_{R}$ and $F R_{V}$ rather measure a mixture of functional richness and divergence.

Ricotta (2005) gave several other criteria for an index of functional diversity, which are only applicable to FR indices. For instance, an index should not decrease when a species is added (the monotonicity criterion) or should not increase when exactly the same species is added (the twinning criterion). These two criteria were also tested in the scenario test (Fig. 4, Table 2) and complied well with nearly all FR indices except $F R_{D}$.

In this study, we restricted our tests to classical versions of the indices without specific patterns of data distribution such as skewness. It would be of further interest to include hypotheses on the data randomisations and test how variations of a certain index (e.g., selection of the distance measure used in $F D_{Q}$ ) react under certain circumstances. However, we only expect slight, fine tuning and not fundamental deviations from the results presented here.

The use of categorical variables is problematic since most tested indices can only be applied to continuous variables. However, our pseudo-test with only continuous variables already revealed that the two transformations proposed (Gower distance followed by a PCoA and the Hill and Smith method) led to a loss of information. When tested for multivariate traits, this was especially true for the Gower distance transformation method followed by a PCoA; for one-dimensional indices, both index matrices calculated on the basis of transformed data correlated only weakly with the matrix based on the untransformed traits. This effect might be even worse when real discrete variables are included in the data set. In this case, the transformation methods via ordination techniques may not be the best choice for the treatment of categorical variables. One way to overcome this problem could be to use a multivariate index based on a distance matrix (e.g., $F D_{Q}$ ) and to transform the trait matrix only via the Gower distance (Podani and Schmera 2006). Since the second transformation step (the ordination technique) is missing in this approach, we expect less loss of information. Another possibility is the approach suggested by Lepš et al. (2006), who recommend calculating dissimilarity between species pairs via the sum of their overlaps for each trait (continuous and categorical). In both approaches (Gower distance and summed overlaps), 
Schleuter, D., Daufresne, M., Massol, F., and Argillier, C. (2010) A User's guide to functional diversity indices, Ecological Monographs, vol. 80, $\mathrm{n}^{\circ} 3,469-484$.

continuous and categorical variables share the same meaning and indicate just to which extent two species are identical.

Otherwise, discrete variables cannot be transformed to continuous variables and processed further with indices designed for this type of variable since functional evenness and divergence have no transposable meaning for discrete traits (i.e., no spatial evenness and divergence of discrete variables, but evenness or variability of trait level distribution). Since categorical and real-valued variables are of completely different character, they have a hard time to find an index in which they can be mixed up (exception see above). A second approach would therefore be to use indices aimed at measuring the specific properties of categorical variables. At present, we propose using the (one-dimensional) indices designed to calculate species diversity, but using trait levels instead of species:

FR (relative richness of trait levels): Corresponding to the relative species richness at a site, we suggest using the number of trait levels present at a site as a proportion of the number of trait levels for all communities together (see $F R_{I s}$, Table 1: IN 1.2).

FE (evenness of trait level distribution): We suggest using Bulla's index of species' evenness (Bulla 1994) based on the contribution of a trait level $\left(A_{l}\right)$ to the overall sample size $A$ (total number of individuals) (see $F E_{s}$ Table 1: IN 2.1).

FD (variability of trait level distribution): We suggest using Index of unalikeability $F D_{c a t}$ by Kader \& Perry (2007) (Table 1: IN 3.3), which corresponds actually to the Simpson index of species diversity (Simpson 1949) but uses trait levels instead of species. $F D_{\text {cat }}$ represents the proportion of possible comparisons, which are unalike, by calculating the contribution of a factor level $\left(A_{l}\right)$ to the overall sample size $A$ (total number of individuals) and subtracts the sum of the squares from 1.

Note that for categorical variables, FE and FD measure approximately the same thing, since both reflect the equitability of distribution (Smith and Wilson 1996). The proposed and other indices on species diversity have been extensively tested (e.g., Washington 1984, Smith and Wilson 1996, Beisel et al. 2003).

\section{Recommendations for users}

Based on the criteria discussed above and the tests performed, we recommend using the multi-dimensional index $F R_{I m}$ to measure $\mathrm{FR}$, or $F R_{I s}$ if only a single trait is considered. Both indices account for intraspecific variability and consider the existence of empty space within the functional trait space and therefore reflect the true functional richness of the community better. Besides, these indices are orthogonal to FE and FD indices. If the user decides to 
Schleuter, D., Daufresne, M., Massol, F., and Argillier, C. (2010) A User's guide to functional diversity indices, Ecological Monographs, vol. 80, $\mathrm{n}^{\circ} 3,469-484$.

compute FR through $F R_{V}$, the data set should not be transformed, even in case of differently scaled traits, since the convex hull calculated with transformed data does not properly represent the functional richness for geometrical reasons, but correlates negatively with the expected results and the other indices for functional richness (results not shown).

FR indices are naturally correlated to species richness. When indices of different communities are compared with each other or when differences between communities are explained with predictor variables, the effect of species richness should therefore be removed from the observed pattern, in order to describe patterns of pure functional diversity. Since the observed relationships are not simply linear and differ between the FR indices, and because of unequal variances, we recommend using null models to remove the effect of species richness rather than using the residuals from a constructed model (method: Gotelli and Graves 1996, example for application: Mason et al. 2007, Prinzing et al. 2008).

Both $F E_{s}$ and $F E_{m}$ can be used to calculate FE. The use of $F E_{s}$ is, however, narrowly restricted to one-dimensional data sets. Similarly, we cannot recommend the use of a specific FD index because all indices reflect the expected changes well, irrespective of whether they are one- or multi-dimensional. However, it should be remembered that not all FD indices are independent of FR indices (Table 4), seemingly because $F D_{\text {var }}$ and some FR indices measure a mixture of FR and FD properties. Further, it should be mentioned that indices based on a distance matrix allow for the use of categorical and continuous variables simultaneously, and they can include intraspecific variability when calculated via the pairwise trait overlap as suggested by Lepš et al. (2006). Specific disadvantages of all indices are further summarized in Table 4.

Concerning categorical variables, we recommend at present avoiding their use if possible, or using indices based on a distance matrix or the one-dimensional indices of species diversity (Table 1: IN 1.2, 2.1, 3.3). In this case, however, the user should keep in mind that the indices designed for categorical variables (especially for FE and FD) do not have the same meaning as their continuous counterparts. The results for the different traits should therefore be averaged over continuous and categorical variables separately, rather than directly averaged over all traits.

In real world measurements, the user comes to face more problems apart from choosing the right index many of which (e.g. weighing of traits) are discussed in Lepš et al. (2006) and Petchey and Gaston (2006). One often occurring problem is that normally not all trait values can be measured for each individual. This is, however, not a problem for the calculation of the indices, since the calculation of all indices (including the newly proposed indices which 
Schleuter, D., Daufresne, M., Massol, F., and Argillier, C. (2010) A User's guide to functional diversity indices, Ecological Monographs, vol. 80, $\mathrm{n}^{\circ} 3,469-484$.

include intraspecific variability) is based on mean trait values and their variability. And how many individuals should be measured for each species? In general the more, the better. However, to restrict sampling effort, a reference value could be the amount of individuals which are necessary to describe the species' trait distribution (Cianciaruso et al. 2009).

\section{ACKNOWLEDGEMENTS}

D. Schleuter was funded by the National Research Agency of France (ANR) within the project Freshwater Fish Diversity (ANR-06-BDIV-010). We thank Linda Northrup for correcting the English, F. Guilhaumon, N.W.H. Mason, D. Mouillot, J. Veslot and S. Villéger for discussion and help with some of the indices, and three anonymous reviewers for their valuable comments.

\section{REFERENCES}

Beisel, J. N., P. Usseglio-Polatera, V. Bachmann, and J. C. Moreteau. 2003. A comparative analysis of evenness index sensitivity. International Review of Hydrobiology 88:3-15.

Bolnick, D. I., R. Svanbäck, J. A. Fordyce, L. H. Yang, J. M. Davis, C. D. Hulsey, and M. L. Forister. 2003. The Ecology of Individuals: Incidence and Implications of Individual Specialization. The American Naturalist 161:1-28.

Bremner, J., S. I. Rogers, and C. L. J. Frid. 2003. Assessing functional diversity in marine benthic ecosystems: A comparison of approaches. Marine Ecology Progress Series 254:11-25.

Bulla, L. 1994. An index of evenness and its associated diversity measure. Oikos 70:167-171. Champely, S. and D. Chessel. 2002. Measuring biological diversity using Euclidean metrics. Environmental and Ecological Statistics 9:167-177.

Chessel, D., A. B. Dufour, and J. Thioulouse. 2004. The ade4 package -I: One-table methods. R News 4:5-10.

Chessel, D. and M. Hanafi. 1996. Analyses de la co-inertie de K nuages de points. Revue de Statistique Appliquée 44:35-60.

Cianciaruso, M. V., M. A. Batalha, K. J. Gaston, and O. L. Petchey. 2009. Including intraspecific variability in functional diversity. Ecology 90:81-89.

Cornwell, W. K., D. W. Schwilk, and D. D. Ackerly. 2006. A trait-based test for habitat filtering: convex hull volume. Ecology 87:1465-1471. 
Schleuter, D., Daufresne, M., Massol, F., and Argillier, C. (2010) A User's guide to functional diversity indices, Ecological Monographs, vol. 80, $\mathrm{n}^{\circ} 3,469-484$.

Díaz, S. and M. Cabido. 2001. Vive la difference: Plant functional diversity matters to ecosystem processes. Trends in Ecology \& Evolution 16:646-655.

Dray, S., A. B. Dufour, and D. Chessel. 2007. The ade4 package - II: Two-table and K-table methods. R News:47-52.

Dumay, O., P. S. Tari, J. A. Tomasini, and D. Mouillot. 2004. Functional groups of lagoon fish species in Languedoc Roussillon, southern France. Journal of Fish Biology 64:970-983.

Escofier, B. and J. Pages. 1994. Multiple Factor-analysis (afmult Package). Computational Statistics and Data Analysis 18:121-140.

Gotelli, N. J. and G. R. Graves. 1996. Null models in ecology. Smithsonian Institution Press, Washington.

Heemsbergen, D. A., M. P. Berg, M. Loreau, J. R. Van Hal, J. H. Faber, and H. A. Verhoef. 2004. Biodiversity effects on soil processes explained by interspecific functional dissimilarity. Science 306:1019-1020.

Hill, M. O. and A. J. E. Smith. 1976. Principal component analysis of taxonomic data with multi-state discrete characters. Taxon 25:249-255.

Hulot, F. D., G. Lacroix, F. O. Lescher-Moutoue, and M. Loreau. 2000. Functional diversity governs ecosystem response to nutrient enrichment. Nature 405:340-344.

Kader, G. D. and M. Perry. 2007. Variability for categorical variables. Journal of Statistics Education 15.

Lande, R. 1996. Statistics and partitioning of species diversity, and similarity among multiple communities. Oikos 76:5-13.

Lavit, C., Y. Escoufier, R. Sabatier, and P. Traissac. 1994. The ACT (STATIS Method). Computational Statistics and Data Analysis 18:97-119.

Lebart, L., A. Morineau, and M. Piron. 2000. Statistique exploratoire multidimensionnelle. 3rd edition. Dunod, Paris.

Lepš, J., F. de Bello, S. Lavorel, and S. Berman. 2006. Quantifying and interpreting functional diversity of natural communities: Practical considerations matter. Preslia 78:481-501.

Mason, N. W. H., P. Irz, C. Lanoiselée, D. Mouillot, and C. Argillier. 2008. Evidence that niche specialization explains species-energy relationships in lake fish communities. Journal of Animal Ecology 77:285-296. 
Schleuter, D., Daufresne, M., Massol, F., and Argillier, C. (2010) A User's guide to functional diversity indices, Ecological Monographs, vol. 80, $\mathrm{n}^{\circ} 3,469-484$.

Mason, N. W. H., C. Lanoiselée, D. Mouillot, P. Irz, and C. Argillier. 2007. Functional characters combined with null models reveal inconsistency in mechanisms of species turnover in lacustrine fish communities. Oecologia 153:441-452.

Mason, N. W. H., K. MacGillivray, J. B. Steel, and J. B. Wilson. 2003. An index of functional diversity. Journal of Vegetation Science 14:571-578.

Mason, N. W. H., D. Mouillot, W. G. Lee, and J. B. Wilson. 2005. Functional richness, functional evenness and functional divergence: the primary components of functional diversity. Oikos 111:112-118.

Mouchet, M., F. Guilhaumon, S. Ville?ger, N. W. H. Mason, J. A. Tomasini, and D. Mouillot. 2008. Towards a consensus for calculating dendrogram-based functional diversity indices. Oikos 117:794-800.

Mouillot, D., W. H. N. Mason, O. Dumay, and J. B. Wilson. 2005. Functional regularity: a neglected aspect of functional diversity. Oecologia 142:353-359.

Petchey, O. L. and K. J. Gaston. 2002. Functional diversity (FD), species richness and community composition. Ecology Letters 5:402-411.

Petchey, O. L. and K. J. Gaston. 2006. Functional diversity: back to basics and looking forward. Ecology Letters 9:741-758.

Petchey, O. L. and K. J. Gaston. 2007. Dendrograms and measuring functional diversity. Oikos 116:1422-1426.

Podani, J. and D. Schmera. 2006. On dendrogram-based measures of functional diversity. Oikos 115:179-185.

Podani, J. and D. Schmera. 2007. How should a dendrogram-based measure of functional diversity function? A rejoinder to Petchey and Gaston. Oikos 116:1427-1430.

Prinzing, A., R. Reiffers, W. G. Braakhekke, S. M. Hennekens, O. Tackenberg, W. A. Ozinga, J. H. J. Schaminée, and v. M. Groenendael. 2008. Less linages - more trait variation: pylogenetically clustered plant communities are functionally more diverse. Ecology Letters 11:809-819.

Purvis, A. and A. Hector. 2000. Getting the measure of biodiversity. Nature 405:212-219.

R Development Core Team. 2008. R: A language and environment for statistical computing. R Foundation for Statistical Computing., Vienna, Austria. URL http://www.Rproject.org.

Rao, C. R. 1982. Diversity and dissimilarity coefficients: a unified approach. Theoretical Population Biology 21:24-43. 
Ricotta, C. 2005. A note on functional diversity measures. Basic and Applied Ecology 6:479486.

Robert, P. and Y. Escoufier. 1976. A unifying tool for linear multivariate statistical methods : the RV coefficient. Applied Statistics 25:257-265.

Simpson, E. H. 1949. Measurement of diversity. Nature 163:688-688.

Smith, B. and J. B. Wilson. 1996. A consumer's guide to evenness indices. Oikos 76:70-82.

Stevens, R. D., S. B. Cox, R. E. Strauss, and M. R. Willig. 2003. Patterns of functional diversity across an extensive environmental gradient: vertebrate consumers, hidden treatments and latitudinal trends. Ecology Letters 6:1099-1108.

Tilman, D., J. Knops, D. Wedin, P. Reich, M. Ritchie, and E. Siemann. 1997. The influence of functional diversity and composition on ecosystem processes. Science 277:13001302.

Villéger, S., N. W. H. Mason, and D. Mouillot. 2008. New multidimensional functional diversity indices for a multifaceted framework in functional ecology. Ecology 89:2290-2301.

Walker, B., A. Kinzig, and J. Langridge. 1999. Plant attribute diversity, resilience, and ecosystem function: The nature and significance of dominant and minor species. Ecosystems 2:95-113.

Washington, H. 1984. Diversity, Biotic and Similarity Indices, A Review with Special Relevance to Aquatic Ecosystems. Water Research 18:653-694.

Whittaker, R. H. 1972. Evolution and measurement of species diversity. Taxon 21:213-251. 
Schleuter, D., Daufresne, M., Massol, F., and Argillier, C. (2010) A User's guide to functional diversity indices, Ecological Monographs, vol. 80, $\mathrm{n}^{\circ} 3,469-484$.

TABLE 1. Index number (IN), index acronym (IA), name, formula and references of the different functional diversity indices. IN starting with 1, 2, or 3 and IA starting with FR, FE or FD refer to Functional Richness, Functional Evenness and Functional Divergence index groups, respectively. Subscrips $s$ and $m$ of index acronyms refer to single (one-dimensional) or multidimensional indices. Notations: $i, s, c, l, t$ individual, species, community, level of trait (for categorical variables), and trait subscripts, respectively; $A_{s}$ abundance of species $s$, $A_{t s}$ abundance of species $s$ when species are sorted following trait $t$ ascending ranking, $A$ total abundance of all species, $A_{l}$ abundance of trait level $l ; I_{s}$ set of individuals from species $s ; L_{t s}$ number of levels of categorical trait $t$ covered by species $s ; L_{t}$ total number of levels of trait $t$; $L$ total number of cross-trait levels; $S_{c}$ set of species present in community $c\left(\left|S_{c}\right|\right.$ number of species present in community $c$ ), $T$ number of traits studied; $V_{c}$ set of vertex species from the convex hull in community $c\left(\left|V_{c}\right|\right.$ is the corresponding number of vertices); $x_{t s i}$ value of trait $t$ in individual $i$ from species $s, X_{t s}$ average value of trait $t$ in species $s, X_{s}$ average value of all traits in species $s$ arranged in a vector; $\Sigma$ variance/covariance matrix of traits; $\operatorname{dist}\left(s, s^{\prime}\right)$ : distance between species pairs based on mean trait values (for continuous variables Euclidean distance is used, for discrete variables the Gower distance), $E$ set of edges connecting species pairs in the minimum spanning tree, $e$ subscript of an edge, dist $(e)$ distance between endpoint species of edge $e, A_{e}$ sum of the abundances of the endpoint species of edge $e ; \mathrm{Q}_{1}$ : lower quartile, $\mathrm{Q}_{3}$ : upper quartile.

\begin{tabular}{llllc}
\hline \hline IN & IA & Name & Formula & Authors \\
\hline 1.1 & $F R_{R}$ & Functional range & $\max _{s \in S_{c}}\left(X_{t s}\right)-\min _{s \in S_{c}}\left(X_{t s}\right)$ & Mason et al. \\
& & & $\max _{s \in \cup S_{c}}\left(X_{t s}\right)-\min _{s \in \cup S_{c}}\left(X_{t s}\right)$ & this study \\
\hline 1.2 & $F R_{I s}$ & Functional richness & $\int_{s \in S_{c}} \max _{s t}\left[1_{s t}(x)\right] d x$ & \\
& & (one-dimensional) & $\int_{s \in \cup S_{c}}\left[1_{s t}(x)\right] d x$ & \\
& & Where $1_{s t}(x)$ is 1 if $x$ is between min and max, & \\
& & else it is 0 & \\
& & for categorical variables : & \\
& & $L_{t c} / L_{t}$ \\
& &
\end{tabular}




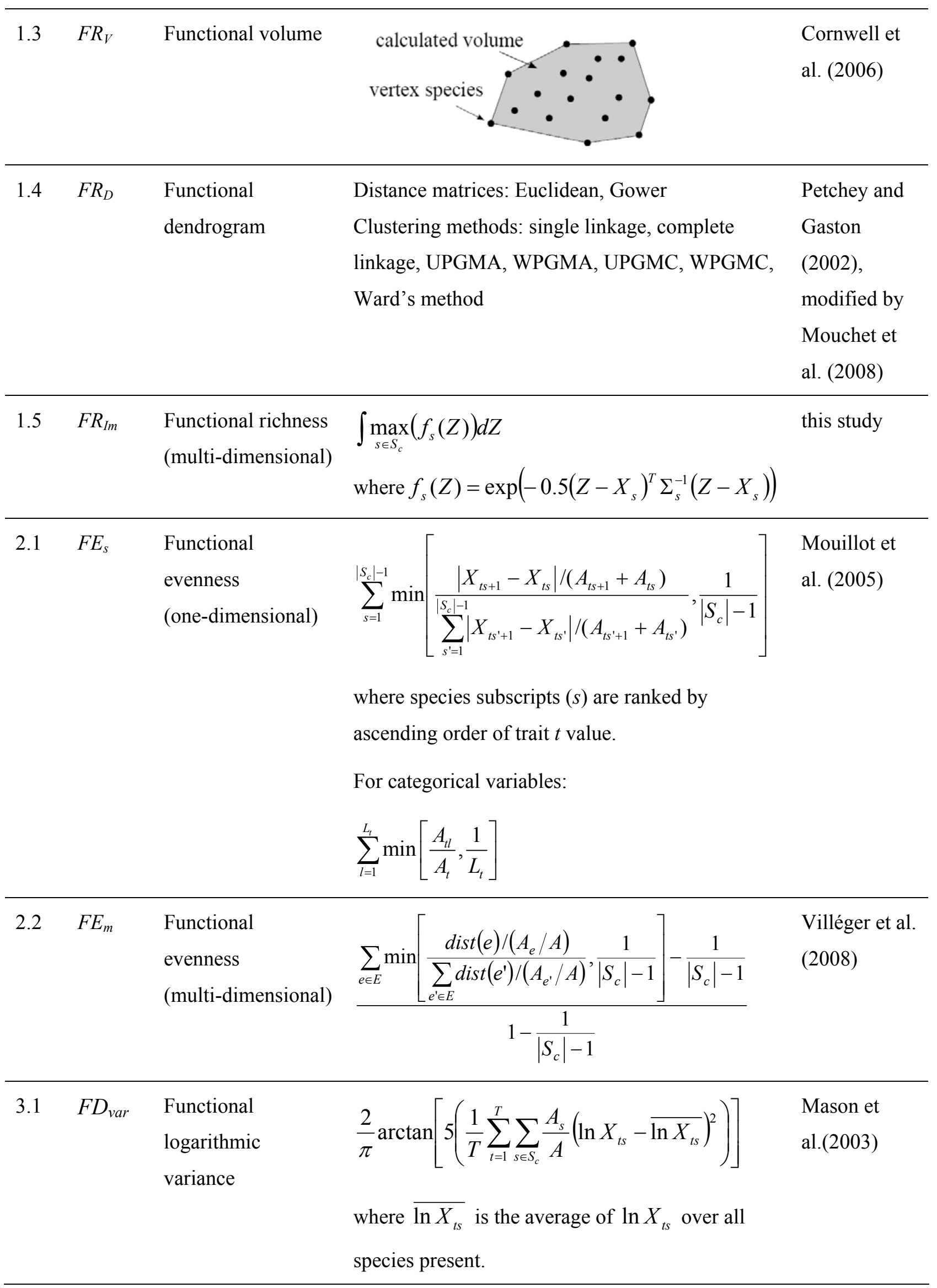




\begin{tabular}{|c|c|c|c|c|}
\hline 3.2 & $F D_{\sigma}$ & $\begin{array}{l}\text { Functional variance } \\
\left(F D_{\text {var }} \text { modified }\right)\end{array}$ & $\sum_{s \in S_{c}} \frac{A_{s}}{A}\left(X_{t s}-\overline{X_{t s}}\right)^{2}$ & $\begin{array}{l}\text { Lepš et al. } \\
(2006)\end{array}$ \\
\hline 3.3 & $F D_{\text {cat }}$ & $\begin{array}{l}\text { Functional } \\
\text { unlikeability }\end{array}$ & $F D_{c a t}=1-\sum_{l=1}^{L_{t}}\left(\frac{A_{l}}{A}\right)^{2}$ & $\begin{array}{l}\text { Kader and } \\
\text { Perry (2007) }\end{array}$ \\
\hline 3.4 & $F D_{s}$ & $\begin{array}{l}\text { Functional } \\
\text { divergence (one- } \\
\text { dimensional) }\end{array}$ & $\begin{array}{l}\frac{Q_{1}\left(Y_{t}\right)-Q_{3}\left(Y_{t}\right)}{\max _{s \in S_{c}}\left(X_{t s}\right)-\min _{s \in S_{c}}\left(X_{t s}\right)} \\
\text { where } Y_{t} \text { is a dummy variable that takes values } X_{t s} \\
\text { with frequency } A_{s} \text {. }\end{array}$ & this study \\
\hline 3.5 & $F D_{Q}$ & $\begin{array}{l}\text { Rao's quadratic } \\
\text { entropy }\end{array}$ & $\sum_{s \in S_{c}} \sum_{s^{\prime} \in S_{c}} \frac{A_{s} A_{s^{\prime}}}{A^{2}} \operatorname{dist}\left(s, s^{\prime}\right)$ & $\begin{array}{l}\text { Rao (1982), } \\
\text { Champely } \\
\text { and Chessel } \\
\text { (2002) }\end{array}$ \\
\hline 3.6 & $F D_{m}$ & $\begin{array}{l}\text { Functional } \\
\text { divergence (multi- } \\
\text { dimensional) }\end{array}$ & $\begin{array}{l}\frac{\Delta d+\overline{d G}}{\Delta|d|+\overline{d G}} \\
\text { where } \Delta d=\sum_{s \in S_{c}} \frac{A_{s}}{A}\left(d G_{s}-\overline{d G}\right) \\
\Delta|d|=\sum_{s \in S_{c}} \frac{A_{s}}{A}\left|d G_{s}-\overline{d G}\right|, d G_{s} \text { is the distance } \\
\text { between species } s \text { and the gravity centre of the } \\
\text { convex hull (coordinates } G_{t}=\frac{1}{|V|} \sum_{s \in V} X_{t s} \text { ), and } \\
\overline{d G} \text { is the average value of } d G_{s} \text { over all present } \\
\text { species. }\end{array}$ & $\begin{array}{l}\text { Villéger et al. } \\
(2008)\end{array}$ \\
\hline
\end{tabular}


TABLE 2. Results for the five index tests T1-T5. Expected changes for the index categories (bold) and observed changes of index values for the different scenarios compared to the initial community and in relation to each other. -: lower than initial community; +: higher than initial community; =: no change. The number of + and - signs indicates the increase compared to the other scenarios.

\begin{tabular}{|c|c|c|c|c|c|c|c|c|c|c|c|c|c|c|c|}
\hline & \multicolumn{3}{|c|}{$\overline{T \text { T1 }}$} & \multicolumn{3}{|c|}{$\overline{T 2}$} & \multicolumn{3}{|c|}{ T3 } & \multicolumn{3}{|c|}{$\overline{T 4}$} & \multicolumn{3}{|c|}{ T5 } \\
\hline & $\mathbf{a}$ & $\mathbf{b}$ & c & $\mathbf{a}$ & $\mathbf{b}$ & c & $\mathbf{a}$ & $\mathbf{b}$ & c & $\mathbf{a}$ & $\mathbf{b}$ & c & $\mathbf{a}$ & b & c \\
\hline Richness & + & + & + & - & - & - & $=$ & $=$ & $=$ & $=$ & $=$ & $=$ & $=$ & $=$ & $=$ \\
\hline$F R_{R}$ & $=$ & + & ++ & - & $=$ & $=$ & $=$ & $=$ & $=$ & $=$ & $=$ & $=$ & $=$ & $=$ & $=$ \\
\hline$F R_{I s}$ & $=$ & + & + & - & - & $=$ & $=$ & $=$ & $=$ & $=$ & $=$ & $=$ & $=$ & $=$ & $=$ \\
\hline$F R_{V}$ & $=$ & + & ++ & - & $=$ & $=$ & $=$ & $=$ & $=$ & $=$ & $=$ & $=$ & $=$ & $=$ & $=$ \\
\hline$F R_{D}$ & ++ & + & - & - & -- & --- & $=$ & $=$ & $=$ & $=$ & $=$ & $=$ & $=$ & $=$ & $=$ \\
\hline$F R_{I m}$ & + & + & + & - & - & - & $=$ & $=$ & $=$ & $=$ & $=$ & $=$ & $=$ & $=$ & $=$ \\
\hline Evenness & + & - & -- & - & --— & -- & - & - & --- & $=$ & + & ++ & -- & -- & - \\
\hline$F E_{s}$ & $=$ & + & + & + & + & ++ & $=$ & $=$ & $=$ & $=$ & - & -- & $=$ & - & - \\
\hline$F E_{m}$ & $=$ & - & -- & - & -- & $=$ & - & -- & --- & $=$ & $=$ & + & -- & - & - \\
\hline Divergence & - & + & ++ & - & + & ++ & - & - & --- & + & ++ & +++ & + & ++ & +++ \\
\hline$F D_{\text {var }}$ & - & + & ++ & - & + & ++ & - & -- & --- & + & ++ & +++ & + & ++ & +++ \\
\hline$F D_{\sigma}$ & - & + & ++ & - & + & ++ & - & - & --- & + & ++ & +++ & + & ++ & +++ \\
\hline$F D_{s}$ & $=$ & - & -- & + & ++ & +++ & $=$ & - & - & + & ++ & +++ & + & ++ & +++ \\
\hline
\end{tabular}


Schleuter, D., Daufresne, M., Massol, F., and Argillier, C. (2010) A User's guide to functional diversity indices, Ecological Monographs, vol. 80, nº 3, 469-484. author-produced version of the final draft post-refeering

the original publication is available at http://www.esajournals.org/ - DOI: 10.1890/08-2225.1

\begin{tabular}{lllllllllllllllllll}
$F D_{Q}$ & - & -- & -- & & - & + & ++ & - & -- & -- & & + & ++ & +++ & & + & ++ & +++ \\
$F D_{m}$ & - & -- & -- & & - & + & ++ & - & -- & --- & & + & ++ & +++ & & + & ++ & +++ \\
\hline
\end{tabular}

* met for all indices concerning functional richness 
Schleuter, D., Daufresne, M., Massol, F., and Argillier, C. (2010) A User's guide to functional diversity indices, Ecological Monographs, vol. 80, $\mathrm{n}^{\circ} 3,469-484$. author-produced version of the final draft post-refeering

the original publication is available at http://www.esajournals.org/ - DOI: 10.1890/08-2225.1

TABLE 3. Axis coordinates of the different functional diversity indices for the first five axes of the reference structure calculated with STATIS over the different species richness levels (here for a data set with three traits)

\begin{tabular}{llrrrrr}
\hline \hline Index group & Index & Axis 1 & Axis 2 & Axis 3 & Axis 4 & Axis 5 \\
\hline Richness & $F R_{R}$ & -0.30 & $-\mathbf{0 . 7 2}$ & 0.08 & -0.06 & 0.09 \\
& $F R_{I s}$ & -0.18 & $-\mathbf{0 . 4 1}$ & -0.29 & -0.15 & $\mathbf{0 . 5 0}$ \\
& $F R_{V}$ & $-\mathbf{0 . 5 0}$ & $-\mathbf{0 . 5 6}$ & 0.03 & -0.24 & -0.16 \\
& $F R_{D}$ & 0.15 & -0.2 & -0.26 & -0.19 & $-\mathbf{0 . 6 5}$ \\
& $F R_{I m}$ & 0.05 & 0.11 & -0.21 & $-\mathbf{0 . 7 6}$ & -0.01 \\
Evenness & $F E_{s}$ & -0.04 & -0.05 & $-\mathbf{0 . 7 1}$ & 0.21 & 0.17 \\
& $F E_{m}$ & -0.05 & 0.00 & $-\mathbf{0 . 6 4}$ & 0.26 & -0.19 \\
& $F D_{v a r}$ & $-\mathbf{0 . 5 4}$ & $-\mathbf{0 . 4 3}$ & 0.20 & 0.35 & -0.19 \\
& $F D_{\sigma}$ & $-\mathbf{0 . 5 8}$ & 0.36 & -0.04 & 0.05 & -0.13 \\
& $F D_{s}$ & $-\mathbf{0 . 7 2}$ & 0.24 & -0.04 & -0.10 & 0.05 \\
& $F D_{Q}$ & $-\mathbf{0 . 8 0}$ & 0.22 & -0.04 & -0.08 & -0.04 \\
& $F D_{m}$ & $-\mathbf{0 . 6 3}$ & 0.37 & 0.01 & -0.01 & 0.06
\end{tabular}


TABLE 4. Indices of functional diversity tested in this study, their properties, correlation with other indices and their disadvantages. The table can be used to choose an index for the data set in question (dimensionality, type of variable, correlation with indices of a different category). A:

Abundance, Adapt.: Adaptation, cat: categorical, Cor: Correlated, IN: Index number, MD: Multi-dimensional, N: number, SR: species richness

\begin{tabular}{|c|c|c|c|c|c|c|c|c|c|}
\hline IS & Authors & Description & MD & $\begin{array}{l}\text { A } \\
\text { incl. }\end{array}$ & $\begin{array}{l}\text { Use with } \\
\text { cat. } \\
\text { variables }\end{array}$ & $\begin{array}{l}\text { Cor. } \\
\text { with SR }\end{array}$ & $\begin{array}{l}\text { Cor. with } \\
\text { indices } \\
\text { from other } \\
\text { categories }\end{array}$ & Disadvantage & IN \\
\hline \multicolumn{10}{|c|}{ Functional richness } \\
\hline$F R_{R}$ & Mason et al. (2005) & Functional range & NO & NO & YES & YES & $F D_{\text {var }}$ & $\begin{array}{l}\text { No consideration of gaps, } \\
\text { one-dimensional }\end{array}$ & $\begin{array}{l}1.1 \\
1.2 \\
\text { (cat) }\end{array}$ \\
\hline$F R_{I s}$ & this study & Individuals functional range & NO & NO & YES & YES & - & $\begin{array}{l}\text { One-dimensional, intra- } \\
\text { specific trait variation needed }\end{array}$ & $\begin{array}{l}1.2 . \\
1.2 \\
\text { (cat) }\end{array}$ \\
\hline$F R_{V}$ & Villéger et al. (2008) & Functional volume & YES & NO & NO & YES & $\begin{array}{l}F D_{\text {var }} \\
F D_{s}, F D_{Q}\end{array}$ & $\begin{array}{l}\text { No consideration of gaps, } \mathrm{SR} \\
\text { has to exceed } \mathrm{N} \text { traits }\end{array}$ & 1.3 \\
\hline$F R_{I m}$ & this study & Functional integral & YES & NO & NO & YES & & $\begin{array}{l}\text { Long computation time, intra- } \\
\text { specific trait variation needed }\end{array}$ & 1.5 \\
\hline \multicolumn{10}{|c|}{ Functional evenness } \\
\hline$F E_{s}$ & Mouillot et al. (2005) & Evenness of trait values & NO & YES & YES & NO & - & One-dimensional & 2.1 \\
\hline
\end{tabular}


Schleuter, D., Daufresne, M., Massol, F., and Argillier, C. (2010) A User's guide to functional diversity indices, Ecological Monographs, vol. 80, $n^{\circ} 3,469-484$. author-produced version of the final draft post-refeering

the original publication is available at http://www.esajournals.org/ - DOI: 10.1890/08-2225.1

\begin{tabular}{|c|c|c|c|c|c|c|c|c|c|}
\hline$F E_{m}$ & Villéger et al. (2008) & $\begin{array}{l}\text { Evenness of minimum } \\
\text { spanning tree branch lengths }\end{array}$ & YES & YES & YES & NO & - & - & 2.2 \\
\hline \multicolumn{10}{|c|}{ Functional divergence } \\
\hline$F D_{s}$ & this study & $\begin{array}{l}\text { Relative range of the } \\
\text { distributional centre }\end{array}$ & NO & YES & NO & NO & $F R_{V}$ & - & 3.4 \\
\hline$F D_{Q}$ & $\begin{array}{l}\text { Rao (1982), } \\
\text { Champely and } \\
\text { Chessel (2002) }\end{array}$ & $\begin{array}{l}\text { Variance of distances } \\
\text { between species }\end{array}$ & YES & YES & YES & NO & $F R_{V}$ & - & 3.5 \\
\hline
\end{tabular}




\section{FIGURE LEGENDS:}

FIG 1. Number of publications containing the term "functional diversity" in title, abstract or keywords. Source: Scopus ${ }^{\circledR}$ (http://www.scopus.com/scopus/search/form.url) until 31.12 .2008

FIG 2. Illustration of the artificial scenarios used to test the behavior of the different indices. There are five different tests (T1-T5) whereby an initial community is modified three times in different ways (Scenarios a-c). Each square represents one community with two trait axes; one dot within a square represents a species. The size of the dot indicates the abundance of the species (small dots reflect one individual; for the other exact abundances used in the tests see text).

FIG 3. Relationship of each of the 12 functional diversity indices with species richness (14 levels from 5-70), here for a data set with three different traits. There are 1000 index values for each species richness level based on randomized trait and abundance data.

FIG 4. Reference structures over the different species richness-specific ordinations gained from the STATIS analysis. a) Reference for three traits, first and second axes; b) reference for three traits, third and fourth axes; c) reference for five traits, first and second axes; d) reference for ten traits, first and second axes. 
Schleuter, D., Daufresne, M., Massol, F., and Argillier, C. (2010) A User's guide to functional diversity indices, Ecological Monographs, vol. 80, $\mathrm{n}^{\circ} 3,469-484$. author-produced version of the final draft post-refeering

the original publication is available at http://www.esajournals.org/ - DOI: 10.1890/08-2225.1

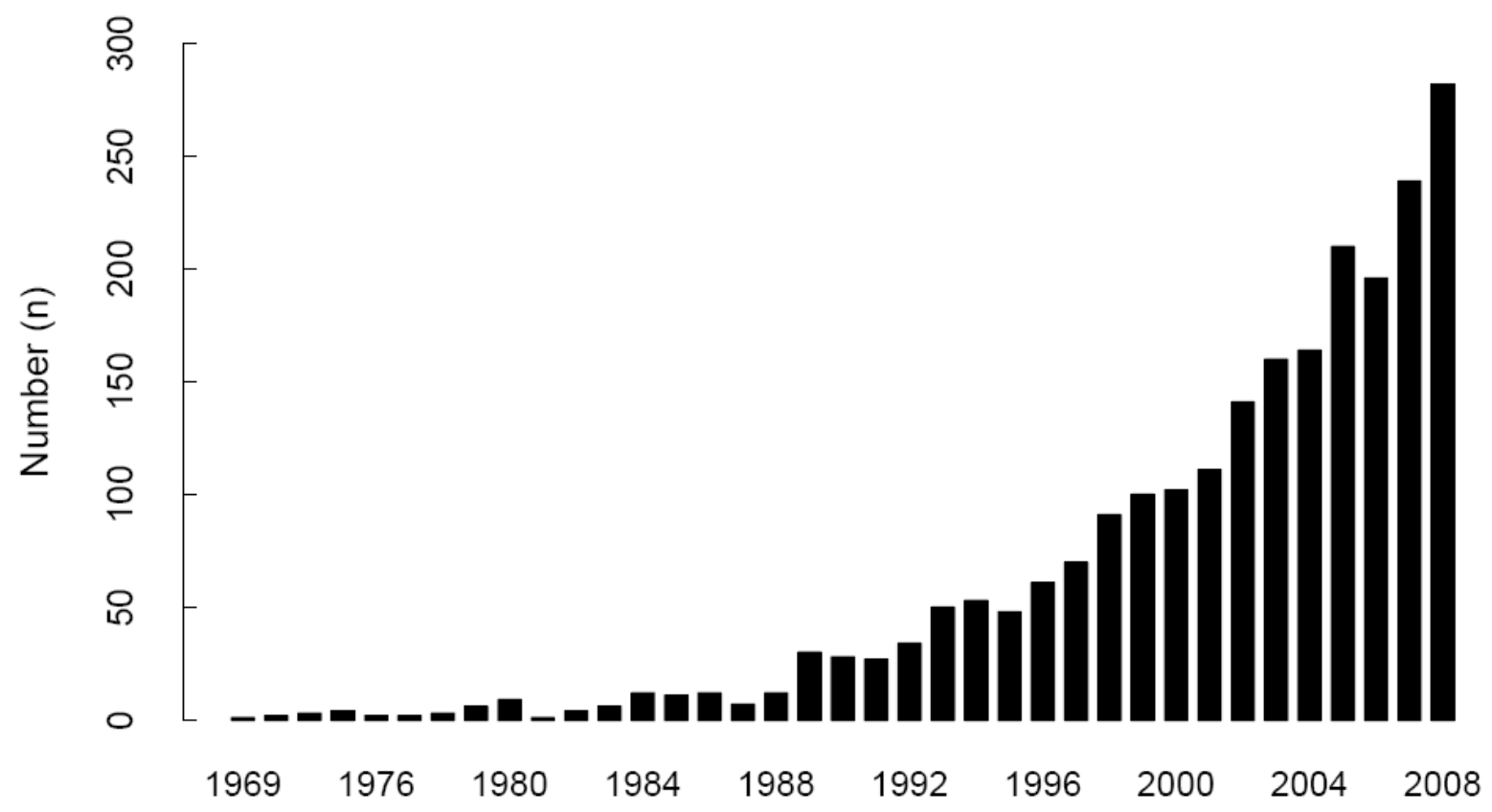

FIGURE 1 
Schleuter, D., Daufresne, M., Massol, F., and Argillier, C. (2010) A User's guide to functional diversity indices, Ecological Monographs, vol. 80, $\mathrm{n}^{\circ} 3,469-484$. author-produced version of the final draft post-refeering

the original publication is available at http://www.esajournals.org/ - DOI: 10.1890/08-2225.1

Initial community

T1

Addition of one species with increasing distance to the initial community

T2

Substraction of nine species at different positions with occasional elimination of an entire trait value

\section{T3}

Stepwise increase of the abundance of one species at the same position in the community

\section{T4}

One species with changing position dominats the community

\section{T5}

Two species with increasing distance to each other dominate the community

\section{Scenarios}

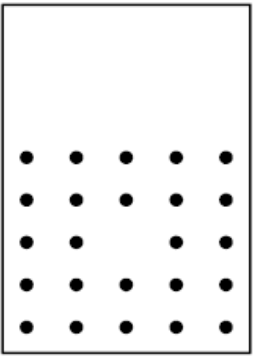

(a)
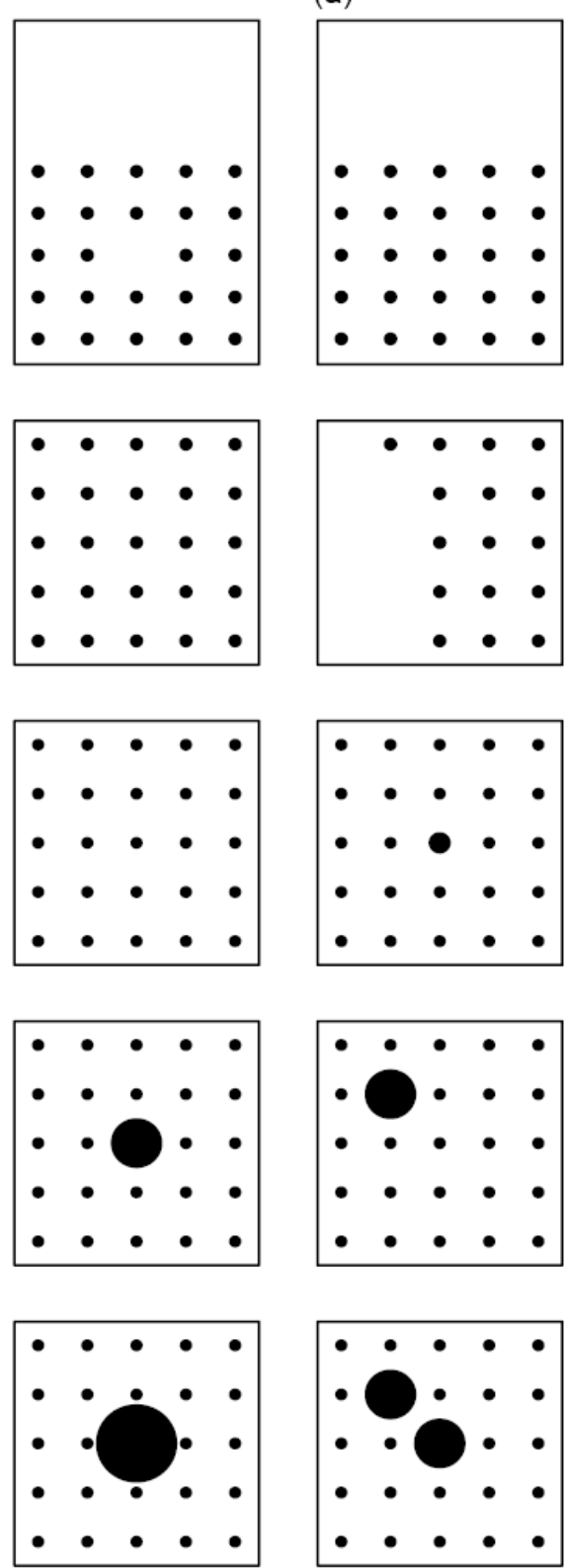

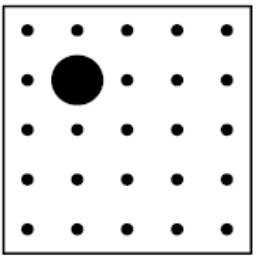

(b)
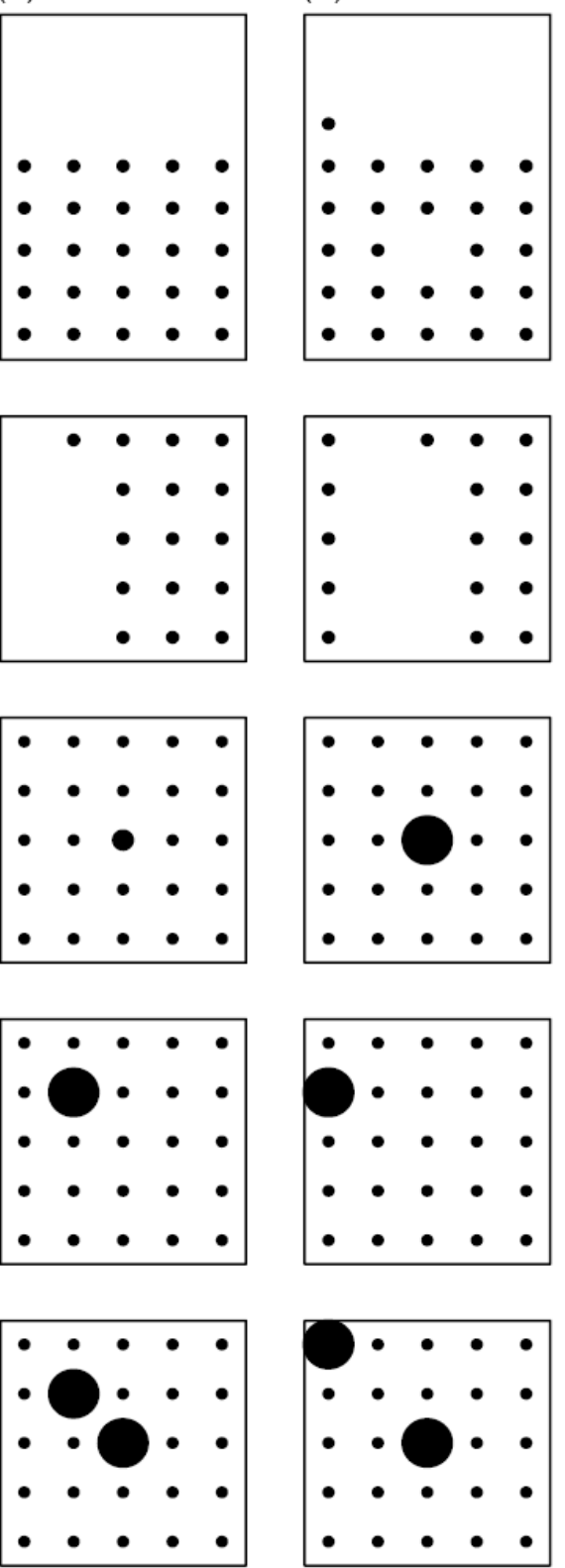

(c)
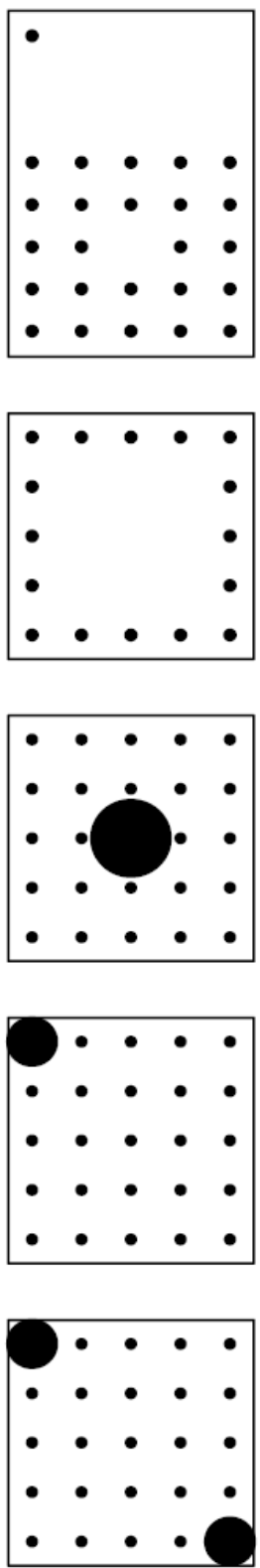

FIGURE 2 
Schleuter, D., Daufresne, M., Massol, F., and Argillier, C. (2010) A User's guide to functional diversity indices, Ecological Monographs, vol. 80, $n^{\circ} 3,469-484$. author-produced version of the final draft post-refeering

the original publication is available at http://www.esajournals.org/ - DOI: 10.1890/08-2225.1
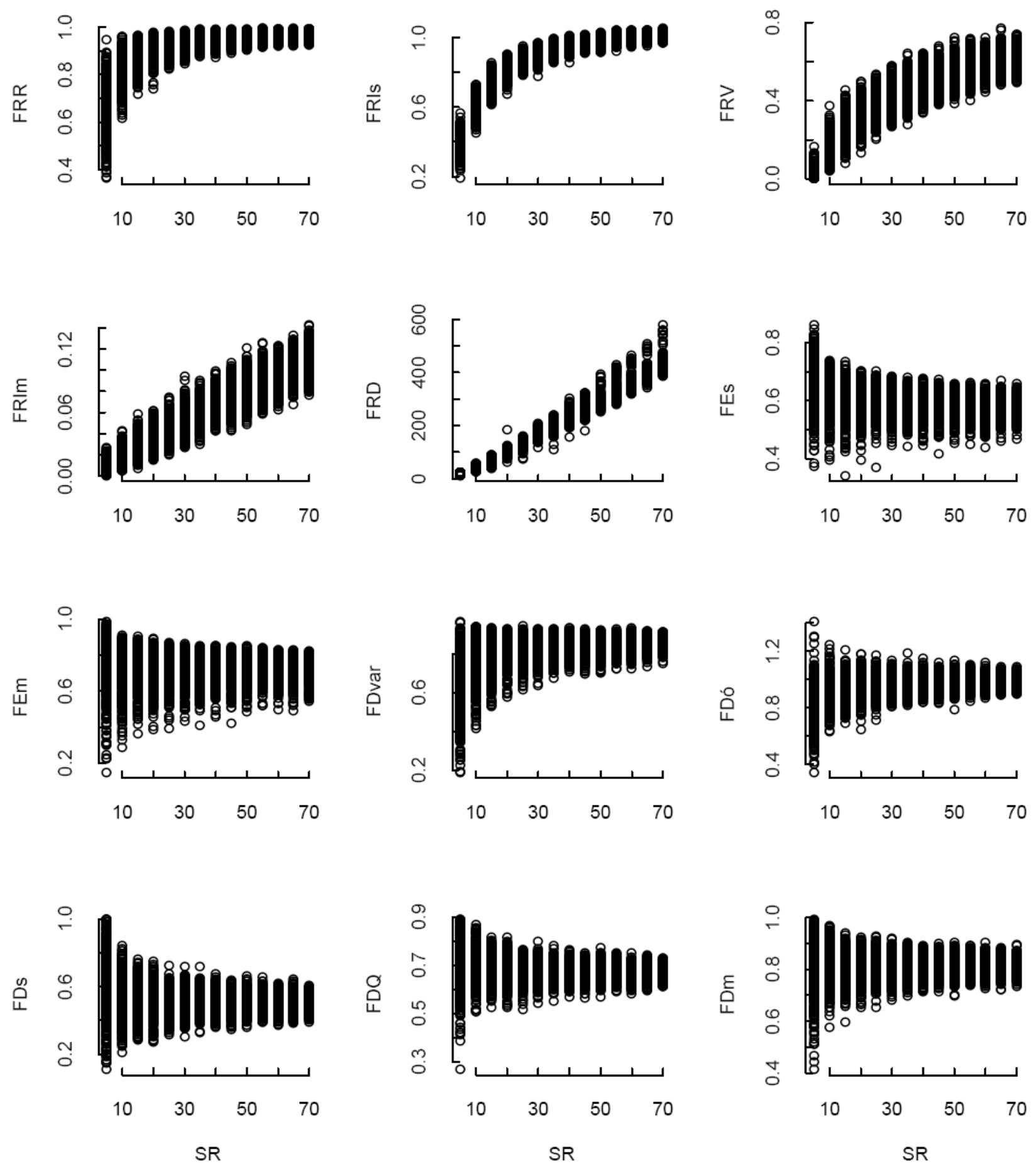

FIGURE 3 
Schleuter, D., Daufresne, M., Massol, F., and Argillier, C. (2010) A User's guide to functional diversity indices, Ecological Monographs, vol. $80, \mathrm{n}^{\circ} 3,469-484$. author-produced version of the final draft post-refeering

the original publication is available at http://www.esajournals.org/ - DOI: 10.1890/08-2225.1
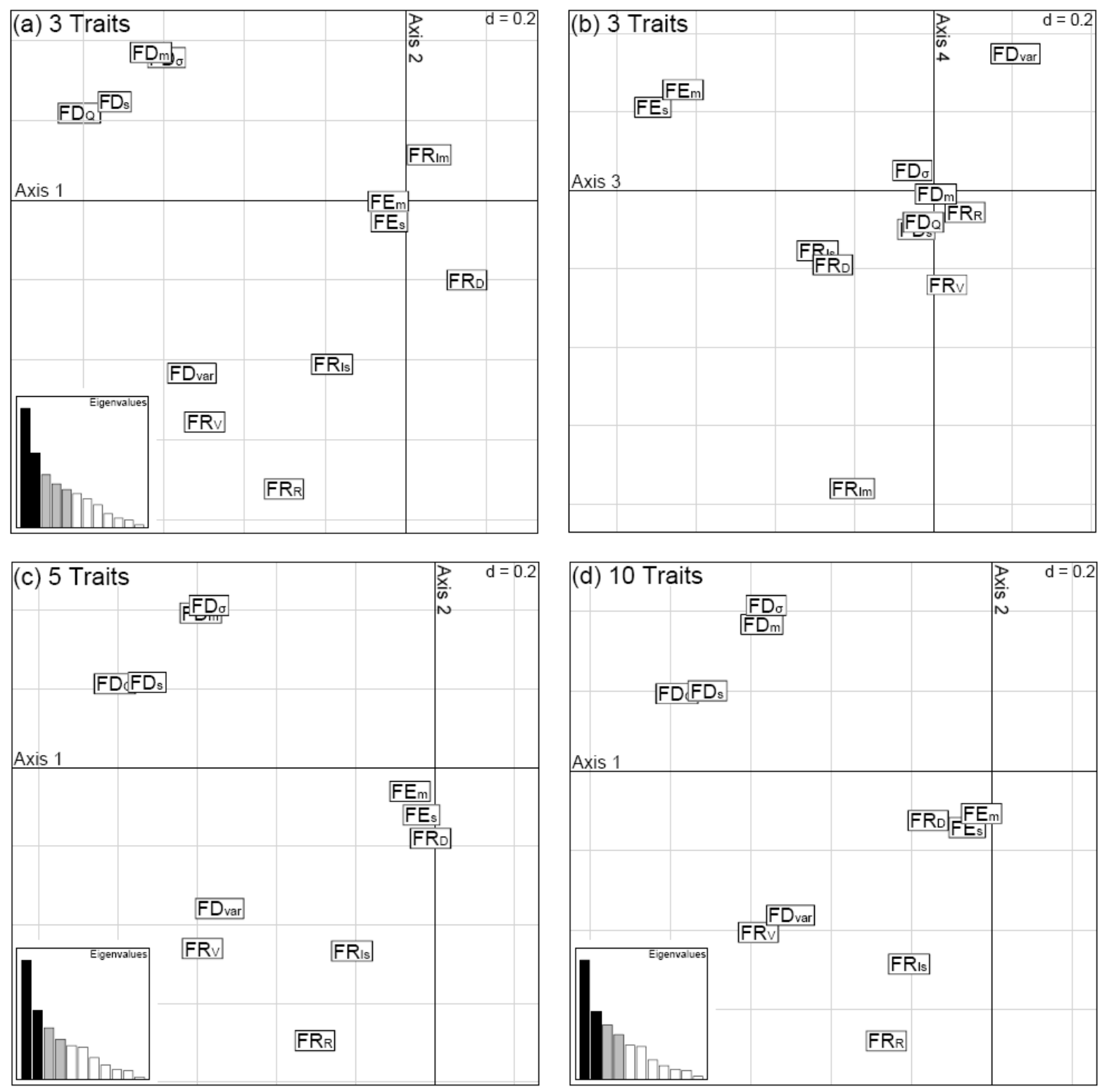

FIGURE 4 


\section{Appendix A: One-dimensional functional richness $\left(F R_{I s}\right)$}

The new one-dimensional functional richness $F R_{I s}$ is based on the functional richness index $F R_{R}$ developed by Mason et al. (2005). However, instead of calculating the trait range of the entire community (based on species mean trait values), $F R_{I s}$ takes individual variability into account by using not the community but the species trait ranges $R_{s}$ :

$$
R_{t s}=\max _{i \in s}\left[x_{i t s}\right]-\min _{i \in s}\left[x_{i t s}\right]=\int 1_{s t}(x) d x
$$

where subscript $t$ stands for trait value, $s$ for species, and $i \in s$ for individual $i$ belonging to species $s$, and $\boldsymbol{1}_{s t}(x)$ is the indicator function for trait $t$ in species $s$. The community's functional richness is then the union of all species trait ranges of a community c, standardized by the union of species trait ranges of all communities together (Fig. A1):

$$
F R_{I s}=\frac{\bigcup_{s \in S_{c}} R_{t s}}{\bigcup_{s \in \cup S_{c}} R_{t s}}=\frac{\int \max _{s \in S_{c}}\left[1_{s t}(x)\right] d x}{\int \max _{s \in \bigcup S_{c}}\left[1_{s t}(x)\right] d x}
$$

Here we use minimum/maximum trait value matrices as input data. Less conservative would be to use for instance $10^{\text {th }}$ and $90^{\text {th }}$ percentiles, confidence intervals or the mean trait values \pm standard deviation.

Depending on the research topic, the minimum/maximum trait value matrices can either be obtained for each sampling site separately or one matrix is built by using measurements from individuals irrespective of their origin. For instance, to identify functional richness patterns in large scale studies with a high number of sampling sites, the effort to collect and measure individuals for each sampling site separately is fastidious. Moreover, individual differences between sampling sites are probably not the focus of such studies. In this case individuals can be collected from different sites to built one global minimum/maximum matrix.

$F R_{I s}$ is standardized by species trait ranges from all communities together to restrict index values between 0 and 1 . In this way, differently scaled traits become comparable, which is especially important because $F R_{I s}$ for all traits is calculated by averaging $F R_{I s}$ calculated for the single traits. This standardization is also quite useful when comparing different communities harboring similar trait spans albeit at different mean trait values. Please note, however, that the value of an individual site is not absolute but might change when the overall range changes (e.g., by the addition of a new site with species that differ in trait values). Further, if index values are similar over communities, a very low range can result in a low overall range and thus in a high $F R_{I s}$. In this case, one should consider whether this trait is informative or whether it can be excluded.

$F R_{I s}$ is advantageous because (i) intraspecific variability and (ii) gaps in the functional trait space are considered. Considering intraspecific variability may be of interest when the variability between species or between populations of different communities differs (in the latter case species' trait values have to be measured for each community separately, but the overall range of a species is calculated using all measurements). To account for gaps in trait space is especially important when species with trait values within the functional trait range are missing or the community contains a species with extreme trait values (see Fig A.1). 
Schleuter, D., Daufresne, M., Massol, F., and Argillier, C. (2010) A User's guide to functional diversity indices, Ecological Monographs, vol. 80, $\mathrm{n}^{\circ} 3,469-484$. author-produced version of the final draft post-refeering

the original publication is available at http://www.esajournals.org/ - DOI: 10.1890/08-2225.1
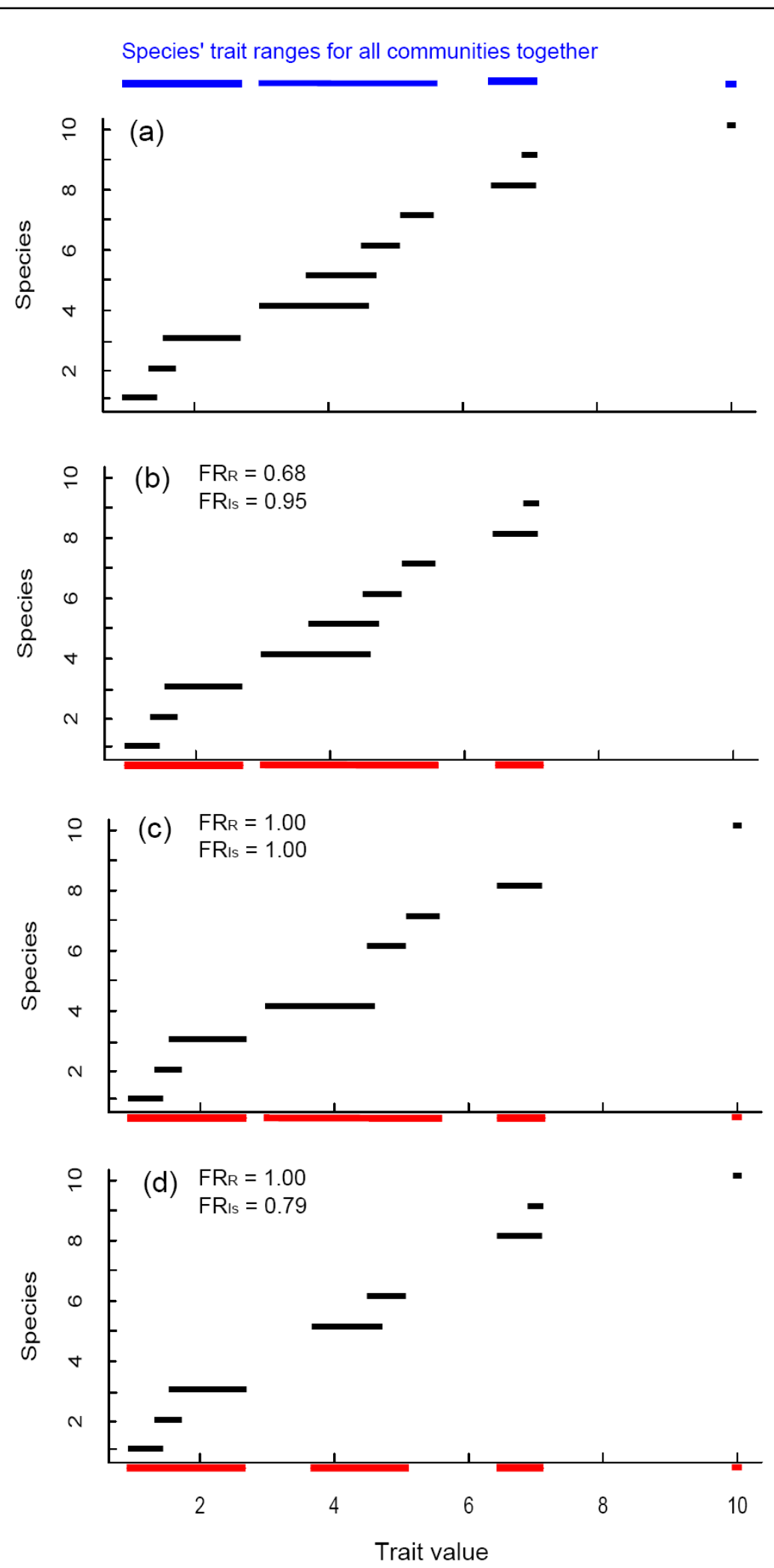

Fig. A1 - Species' trait ranges of (a) all communities together (10 species); (b) the outermost species with an extreme trait value, but low individual variability is removed; (c) two redundant species are removed within the trait range; (d) two functionally exceptional species are removed within the trait range. blue: functional ranges for all species together, red: communities' functional range 
Schleuter, D., Daufresne, M., Massol, F., and Argillier, C. (2010) A User's guide to functional diversity indices, Ecological Monographs, vol. 80, $\mathrm{n}^{\circ} 3,469-484$.

\section{Appendix B: Multi-dimensional functional richness $\left(F R_{I m}\right)$}

$F R_{I m}$ is a new index specifically designed to account for gaps in multidimensional functional trait space and for intraspecific variability. The idea is to consider each species as a fuzzy set in trait space. Thus, species are characterized by their membership functions (or degree of truth functions), $f_{i}$. At a point $x$ of trait space, the membership function of species $i$ is equal to $f_{i}(x)$, which is comprised between 0 and 1 . When $f_{i}(x)=1$, point $x$ belongs surely to species $i$. When $f_{i}(x)=0, x$ does not belong at all to species $i$. For intermediate values of $f_{i}(x), x$ may belong to species $i$, with the degree of truth of this proposition quantified by $f_{i}(x)$.

Two operations on membership functions are useful to compute functional richness. First, the "volume" of a set in trait space is computed by integrating its membership function over all trait space. Second, the membership function of a union of sets is equal to the maximum of all membership functions. Thus, the total "volume" of trait space occupied by a community is:

$$
F R_{\text {Im }}=\int \max _{i}\left[f_{i}(x)\right] d x
$$

An example of such a computation is given in Fig. B1.

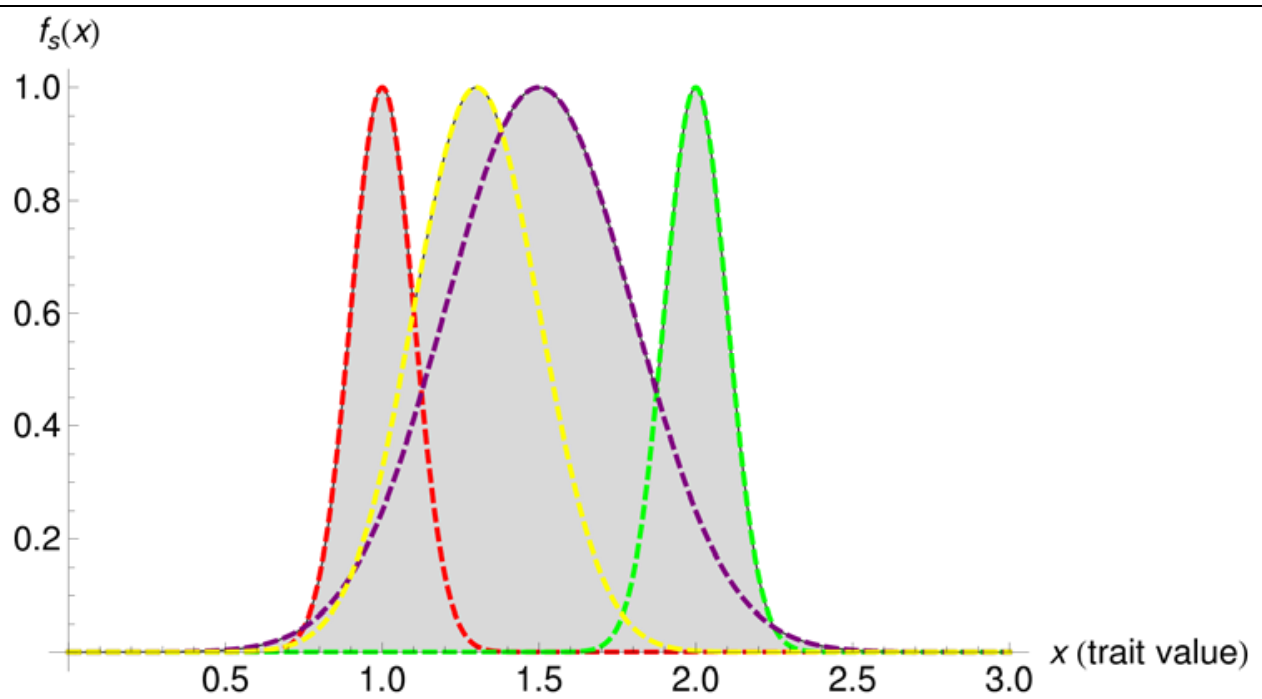

Fig. B1 - An example of $F R_{I m}$ computation (for one-dimensional data) following equation (A.2). Four species are present in the community, with mean trait values 1.0, 1.3, 1.5 and 2.0, and trait standard deviations $0.1,0.2,0.3$ and 0.1 respectively. The four $f_{s}$ functions are represented using colored dashed lines (red, yellow, purple and green, resp.). The value of $F R_{I m}$ is the area in gray.

We chose a simple form for membership functions that could use information on both mean trait values $\left(\mu_{i}\right)$ and trait variance-covariance matrices $\left(\Sigma_{i}\right)$ for each species:

$$
f_{i}(x)=\exp \left[-\frac{1}{2}\left(x-\mu_{i}\right)^{T} \Sigma_{i}^{-1}\left(x-\mu_{i}\right)\right]
$$

When covariances among traits are equal to 0 , the expression for matrix $\Sigma_{i}$ reduces to a diagonal matrix with elements $\sigma_{i j}^{2}$ describing the variance of trait $j$ in species $i$ : 
$f_{i}(x)=\exp \left[-\frac{1}{2} \sum_{j} \frac{\left(x_{j}-\mu_{i j}\right)^{2}}{\sigma_{i j}^{2}}\right]$

\section{Appendix C: One-dimensional functional divergence $\left(F D_{s}\right)$}

Functional divergence measures the clustering of species along the trait axis and is often approached through the weighted variance of trait values. However, it can also be expressed through the relative range of trait distribution. $F D_{s}$ is a new index specifically designed to compute divergence based on the span of trait distribution (calculated as the range between the lower quartile $Q_{1}$ and the upper quartile $Q_{3}$ ). The advantage of $F D_{s}$ in contrast to the variance is that it is always low when species traits are clustered (be it at the edges or in the centre, Fig. C1). The broader the distribution within the range, the higher $F D_{s}$ gets.

The recipe to compute $F D_{s}$ is as follows. First, each species' mean trait value $X_{t s}$ (in a given community) is replicated $A_{s}$ times ( $A_{s}$ is species $s$ abundance in the community):

$Y_{t}=[\underbrace{X_{t s}, X_{t s}, \ldots, X_{t s}}_{\times A_{s}}]$

Example:

When $A_{s_{1}}=3, A_{s_{2}}=5$ and $A_{s_{3}}=2$, we get:

$Y_{t}=\left[X_{t 1}, X_{t 1}, X_{t 1}, X_{t 2}, X_{t 2}, X_{t 2}, X_{t 2}, X_{t 2}, X_{t 3}, X_{t 3}\right]$

In a second step, the $\mathrm{z}^{\text {th }}$ percentiles (here $Q_{1}$ and $Q_{3}$, corresponding respectively to the lower and upper $25 \%$ of the replicated $X_{t s}$ ) of the vector $Y_{t}$ are calculated:

$P_{t}=Q_{1}\left(Y_{t}\right)-Q_{3}\left(Y_{t}\right)$

In the last step, $P_{t}$ is divided by the overall trait range of the community:

$F D_{s}=\frac{P_{t}}{\max _{s \in S_{c}}\left(X_{t s}\right)-\min _{s \in S_{c}}\left(X_{t s}\right)}$ 
Schleuter, D., Daufresne, M., Massol, F., and Argillier, C. (2010) A User's guide to functional diversity indices, Ecological Monographs, vol. 80, $\mathrm{n}^{\circ} 3,469-484$. author-produced version of the final draft post-refeering

the original publication is available at http://www.esajournals.org/ - DOI: 10.1890/08-2225.1

overall range
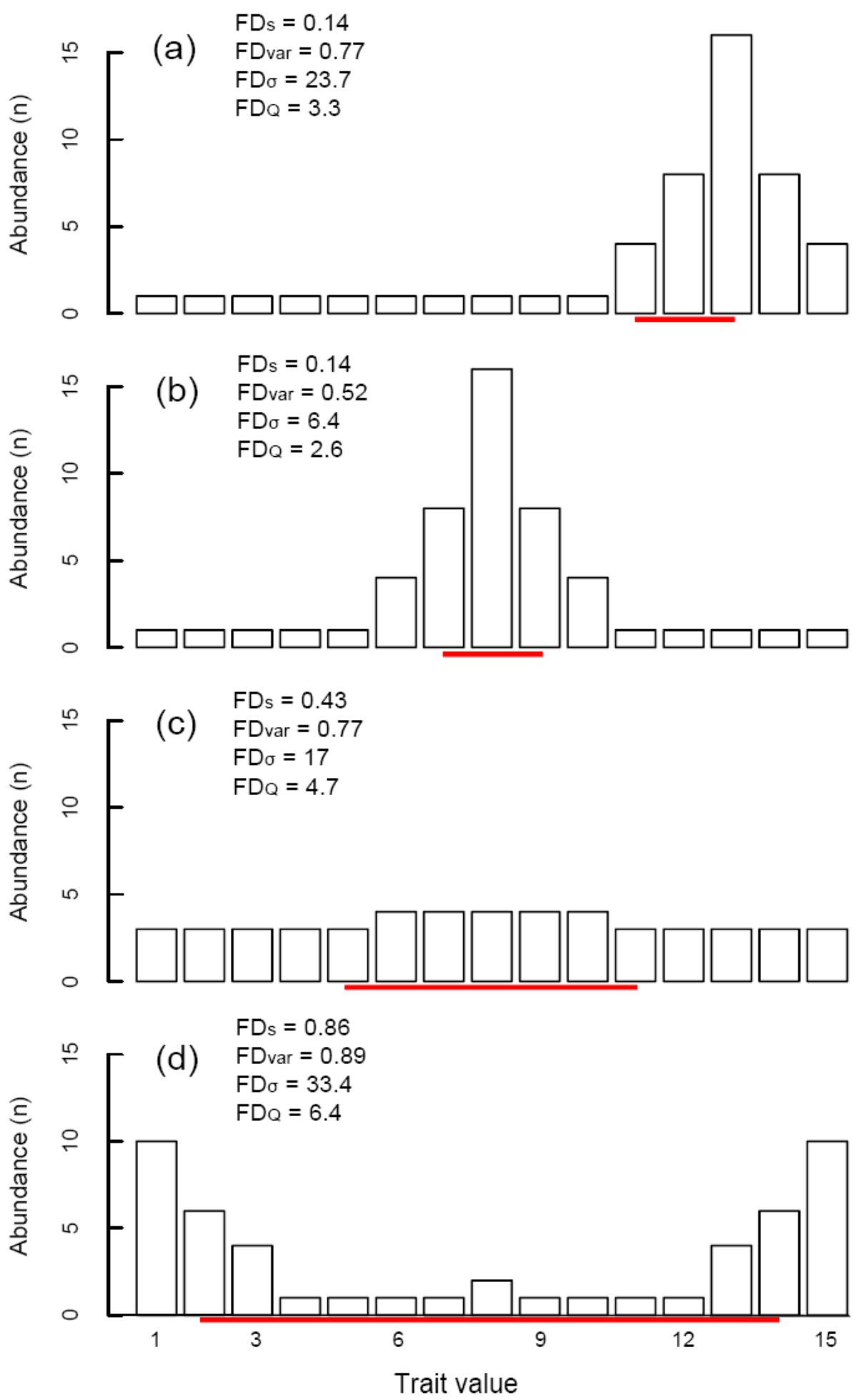

Fig. C1 - 50 individuals, who are distributed into 15 species with different trait values between 1 and 15. In each graph the distributional center of trait values (second and third quartiles) is underlined in red. For each example, all one-dimensional functional divergence values are given. a) one cluster, centered at the right edge; b) one cluster centered in the middle (c) no cluster, distribution close to uniform (d) two clusters at both edges of the trait axis. 
Schleuter, D., Daufresne, M., Massol, F., and Argillier, C. (2010) A User's guide to functional diversity indices, Ecological Monographs, vol. 80, $\mathrm{n}^{\circ} 3,469-484$. author-produced version of the final draft post-refeering

the original publication is available at http://www.esajournals.org/ - DOI: 10.1890/08-2225.1

\section{References:}

Mason, N. W. H., D. Mouillot, W. G. Lee, and J. B. Wilson. 2005. Functional richness, functional evenness and functional divergence: the primary components of functional diversity. Oikos 111:112-118. 